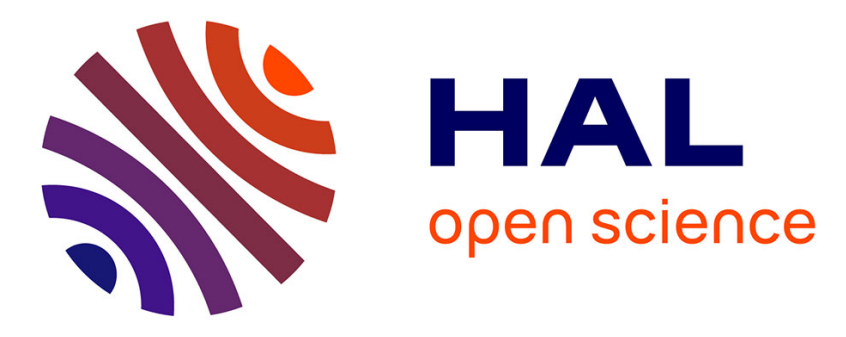

\title{
Poly-etherimide epoxy diamine blends: Conductivity and breakdown voltage measurements at room temperature
}

N. Halawani, Jean-Louis Augé, O. Gain, Virginie Griseri, G. Teyssedre, S. Pruvost

\section{To cite this version:}

N. Halawani, Jean-Louis Augé, O. Gain, Virginie Griseri, G. Teyssedre, et al.. Poly-etherimide epoxy diamine blends: Conductivity and breakdown voltage measurements at room temperature. Polymer Degradation and Stability, 2018, 155, pp.153-161. 10.1016/j.polymdegradstab.2018.05.029 . hal02010751

\section{HAL Id: hal-02010751 \\ https://hal.science/hal-02010751}

Submitted on 25 Nov 2020

HAL is a multi-disciplinary open access archive for the deposit and dissemination of scientific research documents, whether they are published or not. The documents may come from teaching and research institutions in France or abroad, or from public or private research centers.
L'archive ouverte pluridisciplinaire $\mathbf{H A L}$, est destinée au dépôt et à la diffusion de documents scientifiques de niveau recherche, publiés ou non, émanant des établissements d'enseignement et de recherche français ou étrangers, des laboratoires publics ou privés. 


\title{
Poly-etherimide epoxy diamine blends: Conductivity and breakdown voltage measurements at room temperature
}

\author{
N. Halawani ${ }^{1,2}$, J.L. Augé ${ }^{1}$, O. Gain ${ }^{2}$, V. Griseri ${ }^{3}$, G. Teyssèdre ${ }^{3}$ and S. Pruvost ${ }^{2}$ \\ ${ }^{1}$ Univ Lyon, INSA Lyon, UMR CNRS 5005, AMPERE, F- 69622, Villeurbanne, F rance \\ ${ }^{2}$ Univ Lyon, INSA Lyon, UMR CNRS 5223, IMP Ingénierie des Matériaux Polymères, F-69621, Villeurbanne, France \\ ${ }^{3}$ LAPLACE (Laboratoire Plasma et Conversion d'Energie), Université de Toulouse, CNRS, UPS, INPT; Bat 3R3, 118, route de Narbonne, F- \\ 31062 cedex 9 , France \\ *corresponding authors: jean-louis.auge@univ-lyon1.fr
}

Abstract-This paper presents an investigation on the current and breakdown voltage measurements in thermoset-thermoplastic blends based on an epoxy-amine/poly-etherimide phase separated material. Thermosetthermoplastic separated blends could be a novel material for insulation applications and can be compared to epoxy/inorganic composites systems. Pure epoxy network as well as the blends with $10 \mathrm{wt} \%$ of PEI were studied in terms of conduction and transient currents. An ohmic behavior below the threshold field $\left(\mathrm{E}_{\mathrm{th}}\right)$ and space-chargelimited conduction (SCLC) above $\mathrm{E}_{\mathrm{th}}$ are pointed out. Contact emission phenomenon was investigated by means of Schottky model and seems to be valid for both materials. The addition of 5 and 10 wt $\%$ of PEI into the epoxy system showed an increase in the values of breakdown voltage with the increase of the PEI amount.

Keywords: Epoxy; organic-organic blend; insulating material, electrical properties

\section{Introduction}

Epoxy resin is a common electrical insulating polymer, which is used in high voltage resin casted transformers, cable terminations and other accessories [1]-[4]. Epoxy composites and epoxy-thermoplastic blends are two types of material combination made of organic - inorganic and organic - organic mixture, respectively, where the epoxy is the major organic matrix in both situations. Both kinds of materials differ in their composition and thus in their characteristics and applications. Epoxy/filler composites are extensively investigated to observe the influence of the fillers on different properties of the epoxy network and precisely the thermal and electrical ones [5][8]. The studies can be classified depending on the size of the filler used, being micro-sized, nano-sized or a combination of both micro and nano-sized fillers. Moreover, polymer blends and especially epoxy/thermoplastic blends are also extensively studied to show the influence of incorporating a thermoplastic on the mechanical, thermal and solvent resistance properties of the epoxy network [9]- [12].

Epoxy/inorganic composites, with nano and micro sized fillers, have shown mechanical and thermal improvement and have gained more attention in many applications. The addition of these kinds of fillers in the formulation improves for example fire resistance [5],[7],[13],[14]. Khan et al. showed how the mechanical properties of an 
epoxy matrix can be improved with the incorporation of ceramic nanoparticles [15]. During the last decade, some extensive researches were performed to improve the fracture toughness of epoxies with the addition of inorganic fillers, showing an increase in the tensile and young's modulus and the glass transition temperatures [16]-[18].

Electrical properties were more specifically investigated in epoxy composites. Breakdown voltage tests were performed and presented a decrease in the values with the increase of the percentage of micro-particles as shown in several studies [19]-[21]. In general, the incorporation of micro-fillers into an epoxy network leads to a decrease of the breakdown voltage value with respect to pure epoxy and to an increase of the dielectric permittivity values. These micro-composites are good candidates for mechanical achievements as well as for thermal exchange purpose. However; they are not suitable to enhance the dielectric strength of an epoxy network needed for insulations in the high voltage industry.

Over the last decade, the interest in the use of nano-sized fillers as additives to polymer materials (nanocomposites) and specifically in epoxy based materials has increased. An essential criterion in the preparation of this type of material is the dispersion quality of the nanofillers in the epoxy network. Many families of nanofillers were studied, such as silica, alumina, titania, zinc-oxide, barium nitrate, barium titanate and many more used in different nano sizes with or without surface modification. On one hand, some researchers reported an increase of the breakdown values below small critical percentages [6], [22]-[26]. On the other hand, different studies using different percentages and different nanoparticles sizes showed a decrease in the dielectric breakdown of nano-composites in comparison with the neat epoxy network even at low weight fraction. In such cases, the explanation provided is the lack of adhesion at the interface between the epoxy network and the fillers [21],[26]-[28].

Conflicting results on the performance of nanocomposite fillers have been reported and the underlying mechanisms are not sufficiently understood. Several factors can interfere with the incorporation of nanoparticles in the epoxy network on its electrical properties. In order to increase the breakdown voltage value or decrease the permittivity values, the nanoparticles should be relatively small $(<50 \mathrm{~nm})$ and should be functionalized to control the filler/epoxy matrix interface. Otherwise the fillers will act as defects. Adequate surface modification of the fillers improves the interface between the nanoparticles and the epoxy matrix and their dispersion avoiding aggregation or voids formation. Last but not least the content of nanoparticles should not exceed a critical small fraction value above which aggregates can be formed.

In this present work, the studied material is a thermoset/thermoplastic blend having a phase separation phenomenon. This kind of blend is different from the epoxy/inorganic composites as the obtained nodules are formed from an organic material. Some of thermoset/thermoplastic blends are known to enhance the mechanical 
properties of the thermoset network [29],[30]. The thermoplastic nodules act as obstacles absorbing the propagation of cracks and thus increasing the mechanical strength of the blend. From this particular point, an idea was built to study the influence of the phase-separated nodules on the voltage breakdown, the underlying assumption being that the propagation of cracks from mechanical excitation may have similar mechanism as electrical breakdown. Indeed, the different stages of electrical ageing of solid insulation according to the well-accepted model within the dielectric community contain mechanical processes [31],[32]. The electromechanical properties are involved along the ageing process and control, partly or totally, the initial stages with nano-voids formation as well as the final stage of electrical treeing propagation. The thermal, mechanical and dielectric properties of the proposed epoxy/thermoplastic blend were demonstrated in a previous study [33]. Current measurements as well as breakdown voltage measurements are presented in this work.

\section{Experimental}

\section{II.1. Materials}

The epoxy prepolymer used was Diglycidyl ether of bisphenol A, liquid at room temperature, $D G E B A_{\bar{n}=0.15}$ (Araldite LY556 from Huntsman). The curing agent was an aromatic diamine, 4,4'-methylenebis-[2,6diethylaniline], M-DEA supplied by Lonzacure ${ }^{\mathrm{TM}}$. The diamine was added in the stoichiometric ratio, epoxy to amine hydrogen groups equal to 1 , in pure and modified mixtures. The thermoplastic used was Polyetherimide, PEI Ultem 1010, supplied by General electric. The preparation protocol of the pure epoxy network as well as the blend of epoxy and PEI is explained in a previous work [33].

For the designation of the systems, the term DM corresponds to the epoxy-amine (DGEBA-MDEA) system without thermoplastic, which is also called neat network, and DM5PEI and DM10PEI denotes the system DGEBA-MDEA modified with 5 wt.\% and 10 wt.\% of PEI respectively.

\section{II.2. Techniques}

\section{II.2.1. Current measurements}

Samples were processed in disk form of $6 \mathrm{~cm}$ diameter and of thickness between 0.5 and $1 \mathrm{~mm}$. Gold electrodes of 4 $\mathrm{cm}$ in diameter were deposited using a cool sputter coater model SCD 005 from BAL-TEC. An elastomer was laid out at the periphery of the gold electrodes to increase the path between the electrodes (high voltage and ground) and mitigate the influence of the edge of the metallization where the electric field is out of control. The external current was recorded by means of a Keithley 6512 ammeter. Preliminary measurement with elastomer and a guard electrode 
carried out under high vacuum $\left(<10^{-4} \mathrm{~Pa}\right)$ to eliminate spurious currents such as partial discharges and leakage current at the surface of the sample was performed. Results obtained under vacuum or not are the same for the range of voltage investigated (up to $20 \mathrm{kV} \mathrm{DC}$ ).

Each DC electric field step was applied to the sample for 1 hour before the film was put under short-circuit conditions for the same duration at room temperature $\left(21^{\circ} \mathrm{C}\right)$. The same polarization and depolarization procedure was repeated for increasing values of the applied field $\left(1.6,5,8.3,11.6,16.6\right.$ and $\left.25 \mathrm{kV} . \mathrm{mm}^{-1}\right)$. The current was measured continuously along the whole stress cycle in steps of $2 \mathrm{~s}$.

\section{II.2.2. Breakdown Voltage measurements}

Breakdown strength of the samples was measured by applying a linearly increasing DC voltage $(2 \mathrm{kV} / \mathrm{s}) \mathrm{up}$ till the breakdown takes place. The sample of $6 \mathrm{~cm}$ diameter and a thickness between $300 \mu \mathrm{m}$ and $700 \mu \mathrm{m}$ is placed between two steel spherical electrodes $18 \mathrm{~mm}$ in diameter. The whole assembly is immersed in insulating silicon oil to avoid discharges.

\section{II.2.3. Microstructure analysis}

Transmission Electron Microscopy (TEM) analysis was performed on Philips CM120 transmission electron microscope (at the Centre Technologique des Microstructures CT $\mu$ of the University of Lyon) with an accelerating voltage of $80 \mathrm{kV}$. Epoxy samples were trimmed using an ultra-microtome and the slices (60-70 $\mathrm{nm}$ in thickness) were placed onto 300 mesh copper grids for observation.

Atomic Force Microscopy (AFM) images were collected in tapping mode using an AFM Bruker Multimode 8 equipped with Nanoscope V controller. The scanning speed for image acquisition was $0.5 \mathrm{~Hz}$. The used cantilevers are Bruker TAP 150A with a radius of curvature of the tip of $8 \mathrm{~nm}$. Samples used for analysis were trimmed using an ultra-microtome to obtain a smooth surface.

\section{Results and Discussions}

\section{III.1. Transient Currents}

The recorded current, under $5 \mathrm{kV}$ voltage representing a field of $8.3 \mathrm{kV} / \mathrm{mm}$, with respect to time is presented in Figure 1. The polarization current $I_{P}$ follows a transient regime and then stabilizes in both DM and DM10PEI. The quasi-steady-state charging current obtained after $1 \mathrm{~h}$ is taken as the conduction current $\mathrm{I}_{\mathrm{C}}$. The difference between the charging current and the conduction current is the absorption current $\mathrm{I}_{\mathrm{a}}$. Current values were influenced by the presence of PEI in the epoxy network showing higher values for DM10PEI compared to the pure DM sample. Similar features were observed upon applying different voltages starting from 1 up to $15 \mathrm{kV}$. 


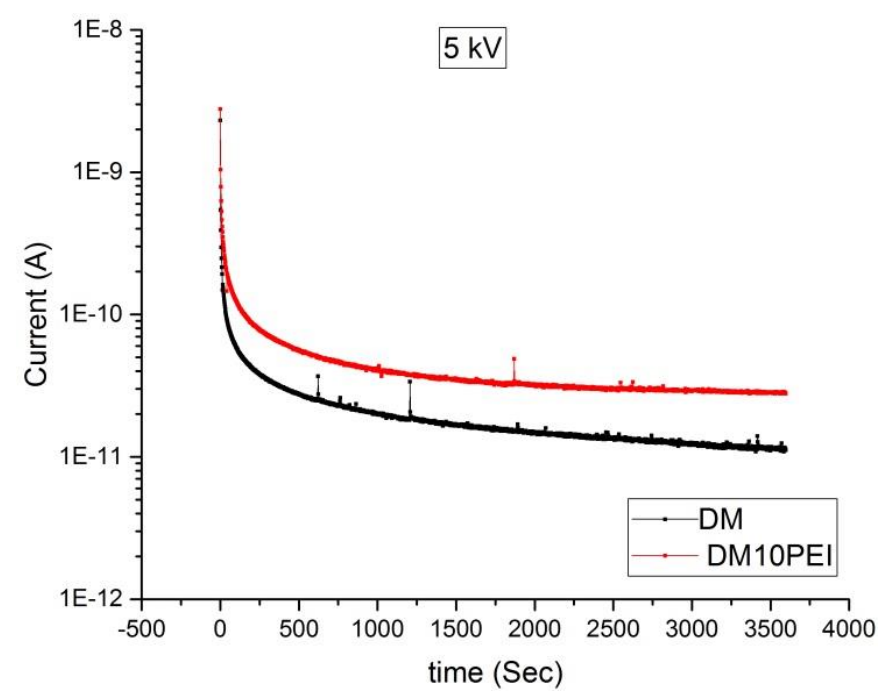

Figure 1: Polarization current curves at $5 \mathrm{kV}$ for DM and DM10PEI

Figure 2 presents a comparison between the absorption currents and the depolarization currents of both DM and DM10PEI. The results are shown for a voltage of $5 \mathrm{kV}$. Similar responses were obtained with all the tested electric fields that is to say the absorption and the depolarization currents followed the same evolution with respect to time and under the same applied electric field. The negative slope of the absorption and discharging currents for DM was measured between $10 \mathrm{~s}$ to $700 \mathrm{~s}$ and found to have the same value of 0.68 . DM10PEI showed similar reversibility, with a slope of 0.65 , for the two responses between $10 \mathrm{~s}$ and $600 \mathrm{~s}$ above which the absorption response starts to decay. This reversibility shows that the polarization phenomenon in this case is dominated by the dipolar movements and is not affected by space charge phenomena [34].
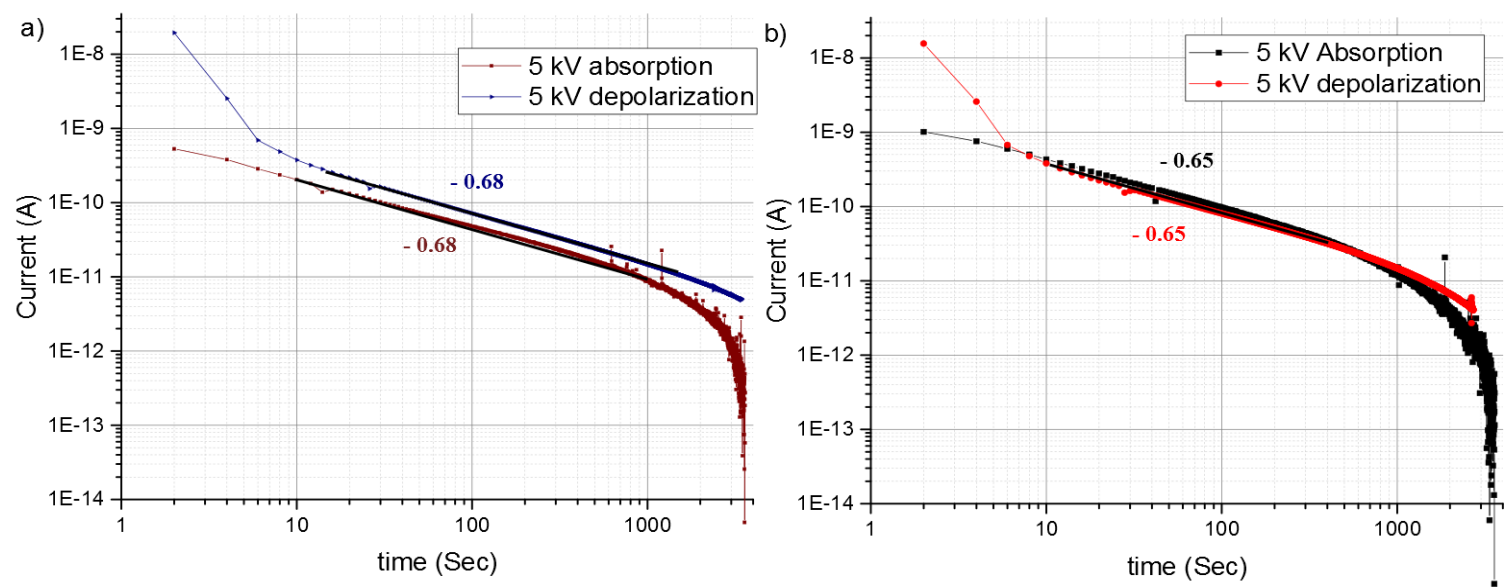

Figure 2: Absorption and depolarization currents under $5 \mathrm{kV}$ for a) DM and b) DM10PEI

The measured currents show obvious dependence with time ( $t$ ) and applied electric field (E). The transient current has been observed to decay following the well-known Curie law [34]: 


$$
I(t)=k \cdot E \cdot t^{-n}
$$

Eq. 1

where $\mathrm{k}$ is a constant that depends on temperature and $\mathrm{n}$ is dependent of the material and can be obtained from the slope between I and $\mathrm{E}$ in isochronal plot. The dependence of isochronal current with respect to applied electric field at different times is shown in Figure 3 and the obtained slopes are extracted in Table 1.

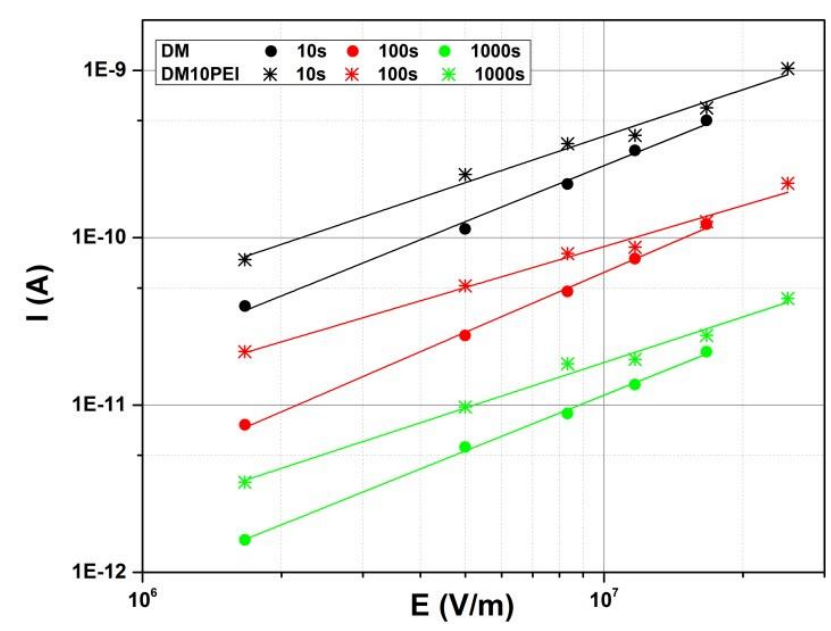

Figure 3: Isochronal currents obtained from depolarization current

Table 1: Obtained slopes of I-E curves from isochronal plots

\begin{tabular}{|c|c|c|c|}
\hline Time (s) & 10 & 100 & 1000 \\
\hline DM & 1.1 & 1.19 & 1.1 \\
\hline DM10PEI & 0.93 & 0.87 & 0.9 \\
\hline
\end{tabular}

The plots of the isochronal discharging currents at 10,100 and 1000 attest the proportionality of the discharging currents to the applied field. The slope varies by less than $9 \%$ and $6 \%$ respectively for DM and DM10PEI with respect to time. The slopes are in the same range, being slightly higher for the pure resin. The obtained slopes for DM can be referred to electrode polarization, dipolar orientation, tunneling and hopping effect [35]. With the addition of PEI the slopes decrease below 1 suggesting the same phenomena as DM. On the other hand, Guillermin et al. suggested in a similar studied material that the decrease of the slope below 1 presents charge injection leading to trapped space charge effects [34], [36],[37]. As this phenomenon was not demonstrated in the reversibility curves, space charge measurements should be experimented to prove it.

\section{III.2. Conduction currents}

An estimation of the conduction current for each applied voltage was carried out from the average of the current measured within the last $20 \mathrm{~s}$ in the quasi-steady-state. Current densities $\mathrm{J}\left(\mathrm{A} / \mathrm{m}^{2}\right)$ at room temperature are plotted in $\log -\log$ scale as function of the applied electric field $\mathrm{E}(\mathrm{kV} / \mathrm{mm})$ for DM and DM10PEI in Figure 4. The two curves present two different conduction modes separated by a threshold field $\mathrm{E}_{\mathrm{th}}$. Below this threshold, both pure epoxy 
DM and DM10PEI have a linear relation between $\mathrm{J}$ and $\mathrm{E}$ with a unit slope corresponding to the Ohmic conduction phenomenon. The threshold field for the blend $(9.2 \mathrm{kV} / \mathrm{mm})$ was lower than that of DM $(12.5 \mathrm{kV} / \mathrm{mm})$ by about 25 $\%$. The presence of PEI might reduce the voltage range of the ohmic regime. This decrease in the threshold field can be an advantage in some applications such as using the epoxy for cable junction.

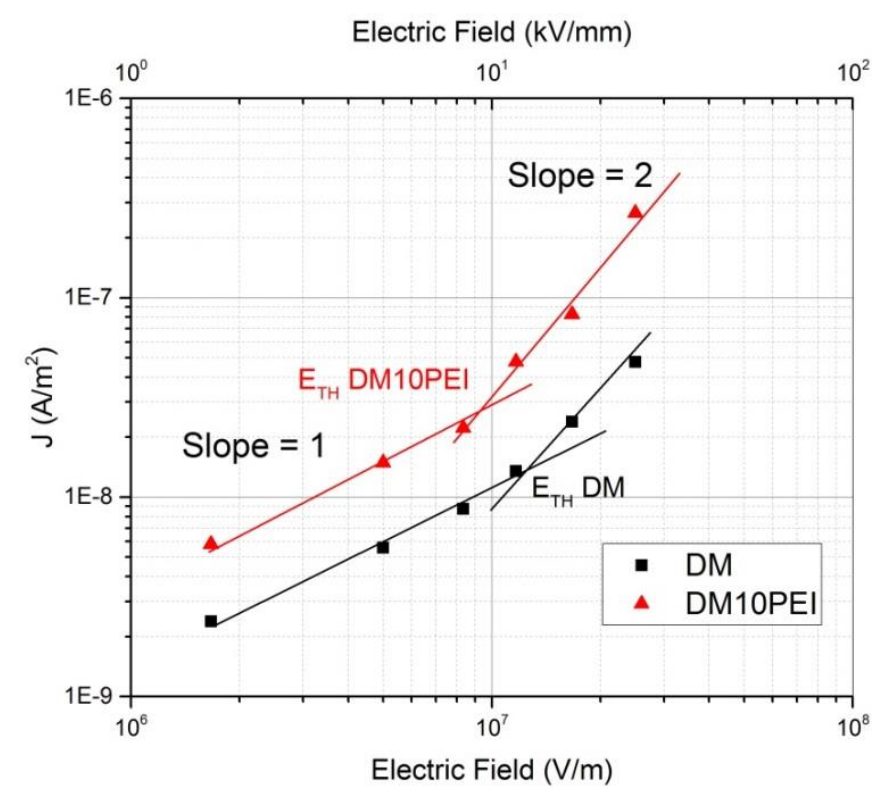

Figure 4: Conduction current density versus applied electric field

Above the threshold field, a non-linearity in the conduction current appears for both samples with a slope of 2 . Similar phenomenon for pure epoxy network with anhydride hardener was obtained with a higher threshold field of $17 \mathrm{kV} \cdot \mathrm{mm}^{-1}$ [36]. The type of hardener has an impact on the matrix structure and the cross-linking ratio and by this way on the motion of the charge carriers.

The conduction phenomenon is dependent on the charge injection behavior as well as the volume conduction behavior. In the following part, both behaviors will be discussed, exploring the Poole-Frenkel mechanism and spacecharge-limited conduction (SCLC) model for the volume conduction phenomenon and the Fowler-Nordheim effect and the Schottky effect to deduce the charge injection mechanism.

\section{III.3. Analysis of conduction process}

\section{III.3.1. Volume-limited conduction}

\section{III.3.1.1 Poole-Frenkel mechanism}

In the Poole-Frenkel mechanism, electrons are trapped in localized states where upon applying either sufficient temperature or high voltage they move to the conduction band and freely in the material. The conductivity in such case obeys the following equation: 


$$
\sigma=\sigma_{0} \exp \left(\frac{\beta_{P F} \sqrt{E}}{k_{B} T}\right)
$$

Eq. 2

where $\mathrm{k}_{\mathrm{B}}$ is the Boltzmann's constant, $\mathrm{T}$ the temperature and $\beta_{\mathrm{PF}}$ the Poole-Frenkel constant [38]. This latter depends on the relative permittivity of the material and follows this law:

$$
\beta_{P F}=\left(\frac{q^{3}}{\pi \varepsilon_{0} \varepsilon_{r}}\right)^{1 / 2}
$$

where $\mathrm{q}$ is the elementary charge, $\varepsilon_{0}$ the vacuum permittivity, $\varepsilon_{\mathrm{r}}$ the relative permittivity of the tested material.

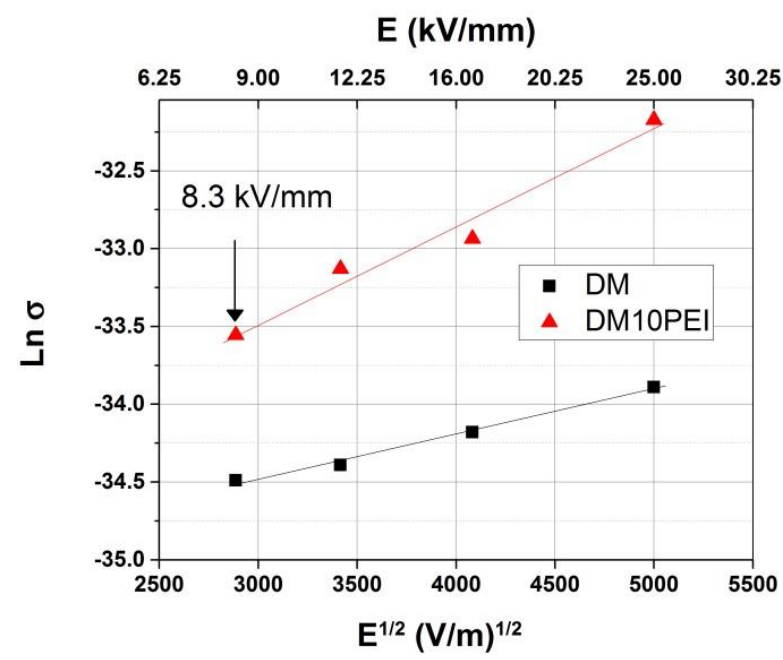

Figure 5: In (conductivity) versus $\sqrt{ } \mathbf{E}$ at room temperature: with $\sigma(\mathrm{S} / \mathrm{cm})$.

Poole Frenkel conduction phenomenon was checked by plotting $\ln \sigma$ versus $\sqrt{E}$ as shown in Figure 5. To fit this law, from Eq. 2 and Figure 5, $\beta_{\mathrm{PF}}$ is calculated from the value of the slope $\left(\beta_{\mathrm{PF}} / \mathrm{k}_{\mathrm{B}} \mathrm{T}\right)$. Its value is equal to $1.2 \times 10^{-24}$ and $2.6 \times 10^{-24} \mathrm{~J} . \mathrm{m}^{-1 / 2} \cdot \mathrm{V}^{-1 / 2}$ for DM and DM10PEI respectively. Calculating $\beta_{\mathrm{PF}}$ theoretically from Eq. 3, the obtained values are $5.33 \times 10^{-24}$ and $5.58 \times 10^{-24} \mathrm{~J} \cdot \mathrm{m}^{-1 / 2} \cdot \mathrm{V}^{-1 / 2}$ for DM and DM10PEI respectively. The values were obtained using the relative permittivity taken from the dielectric measurements at $25^{\circ} \mathrm{C}$ and $1 \mathrm{MHz}\left(\right.$ for $\mathrm{DM} \varepsilon_{\mathrm{r}}=$ 5.17 and for DM10PEI $\varepsilon_{\mathrm{r}}=4.73$ ) [33]. The gap between experimental value of $\beta_{\mathrm{PF}}$ and the calculated one varies by 50-70\%. Thus the conductivity seems not controlled by the Poole-Frenkel law. A similar conclusion was reached when pure epoxy network was measured below its glass transition temperature [39]. This law was only confirmed when the temperature was above the glass transition temperature of epoxy [36]

\section{III.3.1.2 Space-charge-limited conduction model (SCLC)}

Above the threshold field, a non-linearity in the conduction current appears for both samples with a slope of 2 . When the slope is equal to 2 the volume conduction phenomenon fits well with the space-charge-limited conduction model (SCLC). The current density (J) in this case is described by [40]: 


$$
J=\frac{9 \varepsilon_{r} \varepsilon_{0} \mu V^{2}}{8 d^{3}}
$$

Eq. 4

where $\mu$ is the carrier mobility and $d$ is the thickness of the sample.

From the dielectric measurements it was noticed that below $0.1 \mathrm{~Hz}$, no modification of the permittivity was measured, and it was supposed to be under DC condition [33]. The carrier mobility $\mu$ at $10 \mathrm{kV}$ (field of 16kV/mm) is $8.1 \times 10^{-10}$ and $2 \times 10^{-9} \mathrm{~cm}^{2} \mathrm{~V}^{-1} \mathrm{~s}^{-1}$ for DM and DM10PEI respectively. The difference in mobility between the two systems is not significant. These values are in the same range of what is found in the literature for pure epoxy networks in this field range such as $2.3 \times 10^{-10} \mathrm{~cm}^{2} \mathrm{~V}^{-1} \mathrm{~s}^{-1}[36], 1.5 \times 10^{-10} \mathrm{~cm}^{2} \mathrm{~V}^{-1} \mathrm{~s}^{-1}$ [41] and between $10^{-9}$ and $10^{-10}$ $\mathrm{V}^{-1} \mathrm{~s}^{-1}[42]$

\section{III.3.2. Injection-controlled current}

The conduction currents could be controlled by the interface present between the electrode and the sample by the Fowler-Nordheim effect (electron tunneling through an exact or rounded triangular barrier) or the Schottky (jump above the potential barrier). The latter appears generally at high fields or very low temperatures.

\section{III.3.2.1. Fowler-Nordheim}

Fowler-Nordheim model adopts the injection of electrons at the metal-dielectric interface [43]. It is verified by presenting $\ln \frac{\mathrm{J}}{\mathrm{E}^{2}}$ in function of $\frac{1}{\mathrm{E}}$ as shown in Figure 6. This representation did not show a straight line in both pure epoxy and the blend. Therefore the Fowler-Nordheim is not applicable in the studied case. This is an expected fact since Fowler-Nordheim process requires higher electric fields. The injection by tunneling effect through the potential barrier is to be discarded.

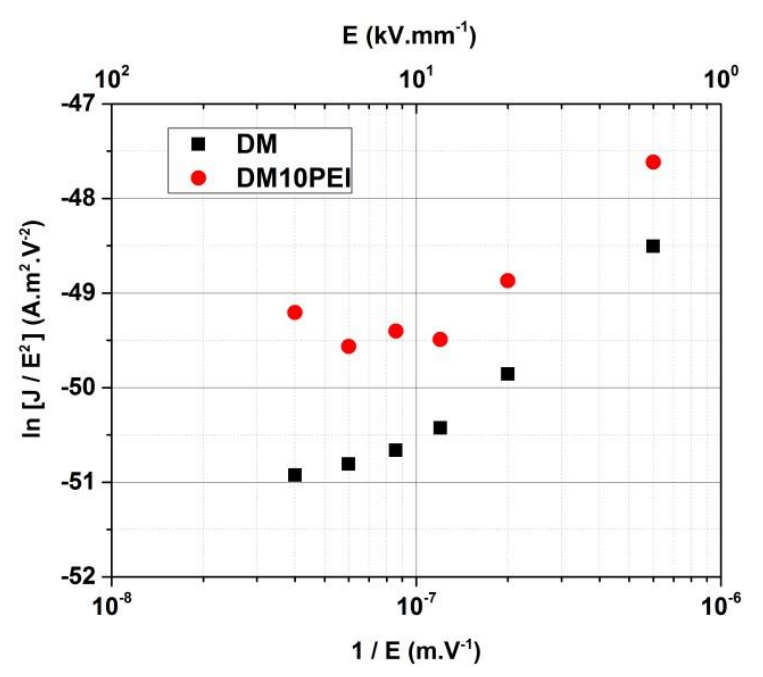

Figure 6: Representation of conduction data in a Fowler-Nordheim plot 


\section{III.3.2.2. Schottky effect}

The current density emitted due to Schottky effect can be described as:

$$
J_{s}=A_{s} T^{2} \exp \left(-\frac{\Phi_{0}-\beta_{s} \sqrt{E_{c}}}{k_{B} T}\right)
$$

Eq. 5

where, $A_{s}$ is the Richardson-Dushman constant for thermionic emission and $E_{c}$ the field at the cathode. $\beta_{s}$ is the Schottky constant:

$$
\beta_{s}=\sqrt{\frac{q^{3}}{4 \pi \varepsilon_{0} \varepsilon_{r}}}
$$

Eq. 6

A plot of $\ln \left(\mathrm{J}_{\mathrm{s}}\right)$ versus $\sqrt{E_{C}}$ is presented in Figure 7 .

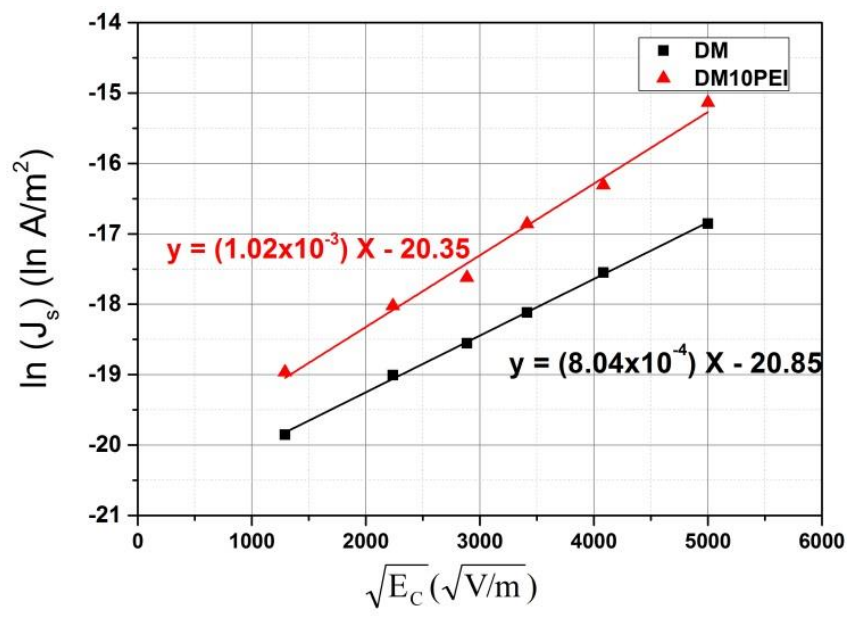

Figure 7: J versus $\sqrt{E_{C}}$ for Schottky

From the obtained slope we can calculate the relative permittivity and compare it with the obtained values from the dielectric measurements using the following equation:

$$
\text { slope }=\frac{\beta_{s}}{k_{B} T}=\frac{1}{k_{B} T} \cdot \sqrt{\frac{q^{3}}{4 \pi \varepsilon_{0} \varepsilon_{r}}}
$$

The obtained values of $\varepsilon_{\mathrm{r}}$ are 3.37 and 2.1 for DM and DM10PEI respectively, which are different from the measured values. It can be argued that the electric field at the cathode is not the average field as it might be modified by trapped space charges. To account of space charge effects, one can consider that there is a distortion of field by introducing a dimensionless alpha parameter:

$$
E_{C}=\alpha \frac{V}{d}
$$

Eq. 8

with $\alpha<1$ for a homocharges dominant at contact and $\alpha>1$ if heterocharges dominate. The field at the cathode is decreased with the existence of homocharges while it is increased if the heterocharges accumulate close to the electrode. The expression of the Schottky current becomes: 


$$
J_{s}=A_{s} T^{2} \exp \left(-\frac{\Phi_{0}-\beta_{s} \sqrt{\alpha \frac{V}{d}}}{k_{B} T}\right)
$$

Eq. 9

The parameter $\alpha$ can now be calculated from the slope obtained using the following equation:

$$
\alpha=\frac{(\text { slope })^{2}\left(k_{B} T\right)^{2} 4 \pi \varepsilon_{0} \varepsilon_{r}}{q^{3}}
$$

Current densities of both DM and DM10PEI are proportional to $\sqrt{\mathrm{E}}$ with slopes in the same range. The calculated values of $\alpha$ are 1.53 and 2.25 for DM and DM10PEI respectively. As the values of $\alpha$ are higher than 1 this would imply that the heterocharges near the cathode increase the local field and tend to decrease the energy barrier at the electrode-polymer interface. With the addition of PEI the injection field at the cathode is increased in comparison with the neat epoxy. Our value of $\alpha$ for the neat epoxy is less than the one reported by [41] evaluated at 2.55 . The Schottky emission process cannot be discarded in this approach where the value of $\alpha$ would increase with the addition of PEI to the pure epoxy network. However, the estimation is dependent on the material in contact with the electrode. It may be possible that an epoxy layer be present at the surface of films, hence the permittivity to be considered for the interface may not be the average one for the polymer blend.

\section{III.4. Breakdown Voltage}

Breakdown voltage provides the probable maximum voltage that a material can withstand before breaking down. For mechanical applications, it was found that introduction of PEI nodules in the epoxy enhances the withstanding of the epoxy. For example, nodules can attenuate mechanical cracks propagation [29]. Starting from this idea of having nodules of PEI, and hypothesizing that this structuration could enhance dielectric strength as well, blends were made using to $5 \mathrm{wt} \%$ and $10 \mathrm{wt} \%$ of PEI for which structures with nodules were made. Figure 8 gives an example for the microstructure of DM5PEI, noting that more complete characterization was presented previously [33]. Besides, PEI has lower relative dielectric values that decreased the permittivity of the blend with respect to that of pure epoxy DM [33].

\section{III.4.1.Morphology}

The structure analysis of the epoxy blends was performed using transmission electron microscopy (TEM) and Atomic Force Microscopy (AFM). In the TEM image of DM5PEI, Figure 8 (a), the dark part corresponds to the PEI nodules and the bright and continuous phase corresponds to the epoxy network. Figure 8 (a) confirms a relatively homogeneous distribution of the PEI nodules in the epoxy network in the blend. The nodules have an ellipse shape in the blend, with the main diameter between $0.5-2 \mu \mathrm{m}$. The AFM image, Figure 8 (b), of a single nodule confirms 
what is observed by means of TEM. An isolated PEI nodule in a DM10PEI sample is shown. It has a major diameter of $1.8 \mu \mathrm{m}$ and a minor diameter of $1.2 \mu \mathrm{m}$.
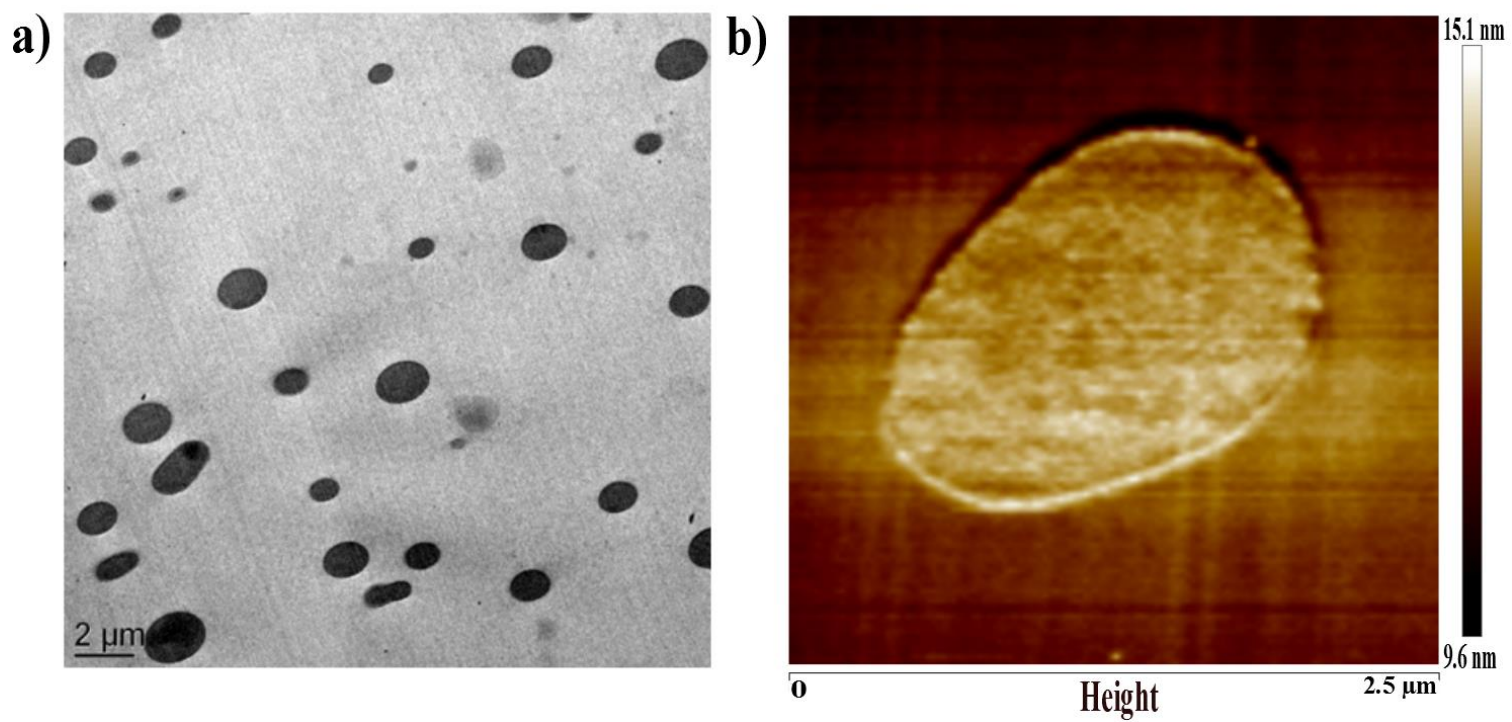

Figure 8: a) TEM image of DM5PEI and b) AFM image of DM10PEI

\section{III.4.2. Weibull Distribution Plot}

The Weibull distribution is the most common failure distribution for electrical breakdown [44]. The values of breakdown voltage were analyzed using the two-parameter Weibull statistical function. Measurements were carried out on a minimum of 10 samples for each system. Two parameters $\alpha$ and $\beta$ can be extracted from the Weibull distribution formula:

$$
\mathrm{F}(\mathrm{x})=1-\exp \left[-(\mathrm{x} / \alpha)^{\beta}\right], \mathrm{x}>0
$$

where $\mathrm{x}$ is the measured breakdown voltage, $\mathrm{F}(\mathrm{x})$ is the cumulative probability, $\alpha$ is the scale parameter and $\beta$ the shape parameter. In the represented graphs, the experimental values are plotted with different percentages using Weibull formula, where all the points are situated in an interval of $95 \%$ of confidence. $\alpha$ and $\beta$ can be deduced from the slope of the probability of breakdown line, where $\alpha$ is the breakdown voltage value at $63.2 \%$ of the probability distribution. Weibull distribution plots of DM, PEI, DM5PEI and DM10PEI are presented in Figure 9 and the corresponding parameters are collected in Table 2. 


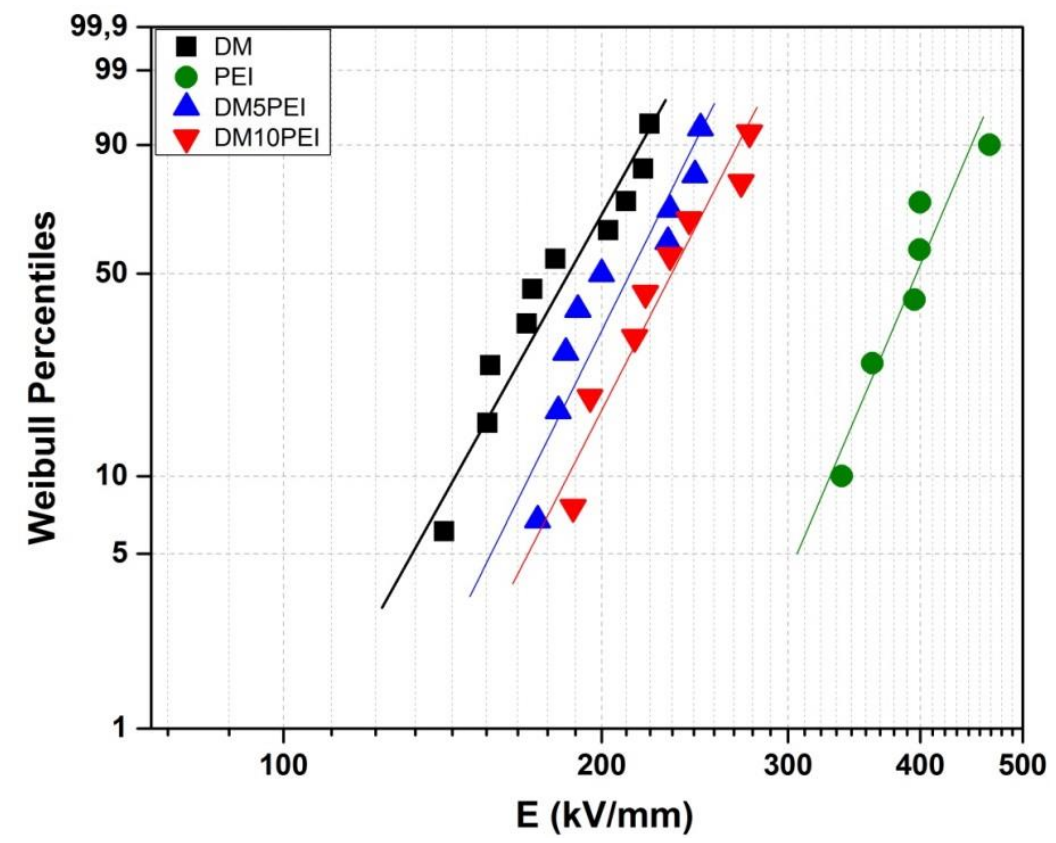

Figure 9: Weibull distribution plot (95 \% confidence interval) for DM, PEI, DM5PEI and DM10PEI

Table 2: Scale and shape parameter from Weibull distribution

\begin{tabular}{|c|c|c|c|}
\hline Sample & Shape parameter: $\boldsymbol{\beta}$ & $\begin{array}{c}\text { Scale parameter: } \boldsymbol{\alpha} \\
(\mathbf{k V / m m})\end{array}$ & $\begin{array}{c}\text { \% with respect to DM } \\
\text { DM }\end{array}$ \\
\hline PEI & 7.6 & 195 & - \\
\hline DM5PEI & 10 & 412 & $\nearrow 14 \%$ \\
\hline DM10PEI & 8.6 & 222 & $\nearrow 25 \%$ \\
\hline
\end{tabular}

The scale parameter $\alpha$ for DM is equal to $195 \mathrm{kV} \cdot \mathrm{mm}^{-1}$; this value for a DC test is higher than the majority of breakdown tests on different systems of epoxy and hardeners. The published values for pure epoxy networks vary from 40 to $100 \mathrm{kV} \cdot \mathrm{mm}^{-1}$ [6], [21], [24], [27],[28],[45] Nevertheless, we have to mention that the common used technique for such characterization is an AC breakdown test, where the values are expected to be lower due to fatigue and energy dissipation. AC breakdown tests will be examined in a future work. PEI demonstrated a higher breakdown voltage $\alpha$ of $412 \mathrm{kV} / \mathrm{mm}$. Blending epoxy with $5 \mathrm{wt} \%$ of PEI has increased the breakdown voltage of the epoxy system by $14 \%$ while when increasing the fraction of PEI to $10 \mathrm{wt} \%$ a gain of $25 \%$ in dielectric strength is possible. The results obtained with the incorporation of nodules confirm the idea of resistance to micro cracks that tend to propagate during a breakdown process. This gives the whole system the ability to withstand higher applied fields. 
Figure 10 shows SEM images of the void tunnel formed in the bulk of the sample due to the electrical breakdown test. The samples are seen from the face and from cross section after breaking the sample in the middle of the hole present after the test. The hole has a circular shape with a diameter in the range 430 to $460 \mu \mathrm{m}$. The hole is narrower in the bulk as seen in Figure 10 (b). The size of the produced hole after the breakdown test is similar to that reported in other studies, such as the work of Iyer et al. on epoxy/inorganic micro-composites [6]. In the sphere-sphere configuration, a quasi-homogeneous field exists at the electrode-dielectric interfaces. The damage could thus equally initiate anywhere within the structure, and should hence first take place in the vicinity of major defects. As a result, it is not possible in this electrode configuration to identify a unique starting point and an end to the damage propagation.
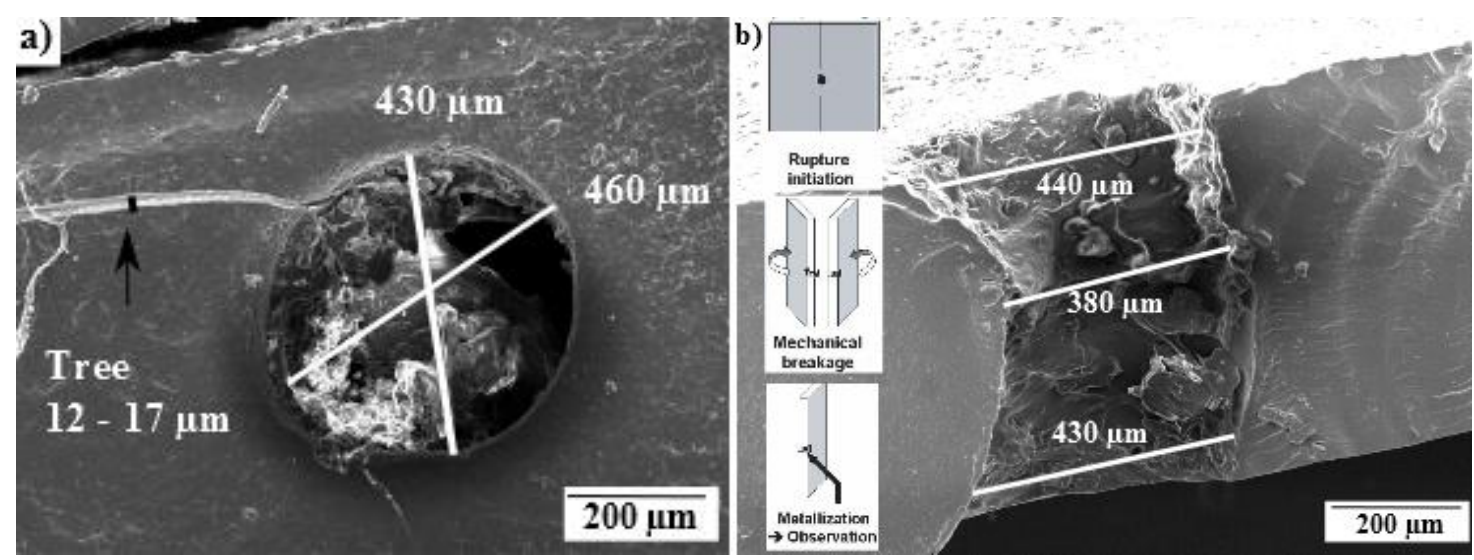

Figure 10: SEM images of the breakdown channel in DM10PEI sample a) face view and b) side view after breaking the sample as illustrated in the schemas

\section{Discussion}

The results obtained can be summed-up as follows. The blends are constituted of an epoxy matrix with PEI nodules of about $1 \mu \mathrm{m}$ side dispersed relatively homogenously in the matrix. A significant increase of the breakdown field is obtained when incorporating 5 wt. \% $(+14 \%)$ or 10 wt. \% (+25\%) of PEI nodules. It must be noted here that unlike what can be observed when dispersing nanoparticles into a polymeric matrix, there is no 'optimum' concentration of the compound at low concentration. This is probably due to the good quality of the dispersion obtained in the current blend, ensured by the separation via a spinodal decomposition mechanism contrary to a nucleation and growth mechanism, compared to the difficulty in maintaining the quality of dispersion of nanoparticles at high concentration.

The increase in the breakdown strength has to be put in relation with values of relatively permittivity for the epoxy (6.4) and of 10 wt. \% blend (5.8) at $0.1 \mathrm{~Hz}$ and with conductivity: conductivity is higher in PEI-containing samples. Anticipating that the permittivity in PEI is lower than that of epoxy, and that the conductivity in PEI is in similar 
range as epoxy [46], these features would lead to field intensification in PEI under AC stress (capacitive distribution). As for under DC measurements (resistive distribution), space charge measurements is needed to provide more explanation. However, internal interfaces in the matrix may provide a more complex behavior than expected. The last information brought by the results is on the possible transport mechanism: conduction would be controlled by SCLC process or by Schottky law supposing that substantial field intensification occurs at the electrodes. So far, to our knowledge, there is no report on space charge measurements in epoxies demonstrating huge heterocharge accumulation. Therefore the SCLC mechanism is privileged. It must be stressed here that SCLC in its strict formulation including ohmic contact and unipolar transport is probably not at play either. In fact most of models combining current limitation at the interface and transport with trapping tend to show a non-linear behavior in a given field range.

Extrapolating transport properties obtained at fields up to $25 \mathrm{kV} / \mathrm{mm}$ up to the breakdown field range which is one order of magnitude higher is questionable. However, the possible reason for the improvement in the breakdown strength could be as follows. G Chen et al. [47] proposed a unified model of transport and breakdown in polyethylene under DC stress supposing that a critical field exists as an intrinsic property of the material, of the order of $400 \mathrm{kV} / \mathrm{mm}$ for PE. If the field exceeds locally this critical value, the breakdown occurs. Space charge build up can be an influential factor in reaching the critical field. So, for the present studied case, the critical field would be related to the epoxy matrix, since according to breakdown strength results, it represents a priori the weak point in the composite. The higher conductivity obtained in the blend could attenuate space charge build up in the material and the field distortion that goes with it. As a consequence, the material could withstand higher field. This is one view of the breakdown mechanism. An alternative explanation would be the role of nodules as barrier to microcracks where they can improve electrical treeing resistance as well.

Previous works on incorporation of nano and/or micro inorganic-fillers to the epoxy network has shown globally a decrease in the breakdown voltage value. These fillers had higher electrical conductivity and permittivity values with respect to the pure epoxy matrix and thus acted as defects in the material favoring the breakdown at lower voltages [6],[19],[20],[48]. In our studied blends, the PEI nodules have similar electrical conductivity values as well as lower permittivity where there was an enhancement in the breakdown voltage of the blend with respect to the pure epoxy network. This increase in the value can be due to the form of the micro-nodules of PEI that are distributed into the epoxy matrix as well. 


\section{Conclusion}

In this paper, electrical characterization of an organic-organic blend composed of epoxy with homogenously distributed thermoplastic nodules is examined and compared to the pure epoxy system. All measurements were studied at room temperature. Current measurements demonstrated Ohmic conduction phenomenon below the threshold field. Above the threshold field two possible approaches were studied. It is suggested that the current is controlled by volume phenomena through SCLC approach. Schottky model was also investigated and could also explain the features. Both materials DM and DM10PEI showed contact emission phenomenon at the interface between the electrodes and the sample. Further studies must be considered for this kind of measurement with variation of temperatures and especially monitoring the distribution of the space charge inside the sample. Monitoring the space charge will also give a wider vision on the breakdown voltage mechanism that has shown an increase in the strength with the increase of the wt $\%$ of PEI into the epoxy network. This enhancement is rarely seen in literature especially with the incorporation of micro-fillers as they act as defects. It can be explained by two different aspects. The first aspect is by taking into consideration that the PEI nodules, homogenously distributed in the epoxy network as seen by means of TEM, might act as obstacles for the breakdown voltage of the blends. The second aspect is by considering the fact that the blends have higher conductivity than the pure epoxy network; this leads to the possibility of the attenuation of the buildup of space charge in the material and consequently giving the blend the ability to withstand higher applied fields. Thus further investigations precisely monitoring the distribution of the space charge inside the sample are needed to confirm these assumptions.

\section{Acknowledgements}

The authors wish to thank Pierre Alcouffe for realizing the TEM image at the Centre Technologique des Microstructures CT $\mu$ of the University of Lyon. The French Ministry of Education and Research is gratefully recognized for providing a grant for this project and the Ecole Doctorale Electronique Electrotechnique Automatique de Lyon ED160 for their financial support.

\section{References}

[1] Fukunaga, K., Tan, M. \& Takehana, H. New partial discharge detection method for live UHV/EHV cable joints. IEEE Transactions on Electrical Insulation 27, 669-674 (1992).

[2] Nadolny, Z., Braun, J. M. \& Densley, R. J. Investigation of partial discharge pulse shapes occurring at interfaces in model joints. in Proceedings of the 1998 IEEE 6th International Conference on Conduction and Breakdown in Solid Dielectrics, 1998. ICSD '98 119-122 (1998).

[3] Dakin, T. W. Application of Epoxy Resins in Electrical Apparatus. IEEE Transactions on Electrical Insulation EI-9, 121-128 (1974). 
[4] Imai, T. et al. Effects of nano- and micro-filler mixture on electrical insulation properties of epoxy based composites. IEEE Transactions on Dielectrics and Electrical Insulation 13, 319-326 (2006).

[5] Tanaka T. Dielectric nanocomposites with insulating properties. IEEE Transactions on Dielectrics and Electrical Insulation 2005;12: 914-28.

[6] Iyer, G., Gorur, R. S., Richert, R., Krivda, A. \& Schmidt, L. E. Dielectric properties of epoxy based nanocomposites for high voltage insulation. IEEE Transactions on Dielectrics and Electrical Insulation 18, 659-666 (2011).

[7] Tsekmes IA, Morshuis PHF, Smit JJ, Kochetov R. Enhancing the thermal and electrical performance of epoxy microcomposites with the addition of nanofillers. IEEE Electrical Insulation Magazine 2015;31:32-42.

[8] Anderson, B. J. Thermal stability and lifetime estimates of a high temperature epoxy by Tg reduction. Polymer Degradation and Stability 98, 2375-2382 (2013).

[9] Hedrick JL, Yilgör I, Wilkes GL, McGrath JE. Chemical modification of matrix Resin networks with engineering thermoplastics. Polymer Bulletin 1985;13:201-8.

[10] Bonnet, A., Lestriez, B., Pascault, J. P. \& Sautereau, H. Intractable high-Tg thermoplastics processed with epoxy resin: Interfacial adhesion and mechanical properties of the cured blends. J. Polym. Sci. B Polym. Phys. 39, 363-373 (2001).

[11] Oyanguren PA, Riccardi CC, Williams RJJ, Mondragon I. Phase separation induced by a chain polymerization: Polysulfone-modified epoxy/anhydride systems. J Polym Sci B Polym Phys 1998;36:1349-59.

[12] Bonnet A, Pascault JP, Sautereau H, Taha M, Camberlin Y. Epoxy-Diamine Thermoset/Thermoplastic Blends. 1. Rates of Reactions before and after Phase Separation. Macromolecules 1999;32:8517-23.

[13] Guo, J. et al. Study on electrical properties of micro-nano structured epoxy composites. in Proceedings of 2014 International Symposium on Electrical Insulating Materials 441-444 (2014)

[14] Zhou, W. Effect of coupling agents on the thermal conductivity of aluminum particle/epoxy resin composites. J Mater Sci 46, 3883-3889 (2011).

[15] Khan, R. et al. Facile synthesis of epoxy nanocomposite coatings using inorganic nanoparticles for enhanced thermo-mechanical properties: a comparative study. J Coat Technol Res 13, 159-169 (2015).

[16] Lee, J. \& Yee, A. F. Inorganic particle toughening I: micro-mechanical deformations in the fracture of glass bead filled epoxies. Polymer 42, 577-588 (2001).

[17] Kinloch, A. J. et al. Toughening structural adhesives via nano- and micro-phase inclusions. The Journal of Adhesion 79, 867-873 (2003).

[18] Balakrishnan, S., Start, P. R., Raghavan, D. \& Hudson, S. D. The influence of clay and elastomer concentration on the morphology and fracture energy of preformed acrylic rubber dispersed clay filled epoxy nanocomposites. Polymer 46, 11255-11262 (2005).

[19] Li, Z., Okamoto, K., Ohki, Y. \& Tanaka, T. Effects of nano-filler addition on partial discharge resistance and dielectric breakdown strength of Micro-A12O3Epoxy composite. IEEE Transactions on Dielectrics and Electrical Insulation 17, 653-661 (2010).

[20] Hu, Y., Smith, R. C., Nelson, J. K. \& Schadler, L. S. Some mechanistic understanding of the impulse strength of nanocomposites. in 2006 IEEE Conference on Electrical Insulation and Dielectric Phenomena 31-34 (2006).

[21] Singha, S. \& Thomas, M. J. Dielectric properties of epoxy nanocomposites. IEEE Transactions on Dielectrics and Electrical Insulation 15, 12-23 (2008).

[22] Imai, T. et al. Improving Epoxy-based Insulating Materials with Nano-fillers toward Practical Application. in Conference Record of the 2008 IEEE International Symposium on Electrical Insulation, 2008. ISEI 2008 201204 (2008).

[23] Ding, H. Z. \& Varlow, B. R. Effect of nano-fillers on electrical treeing in epoxy resin subjected to AC voltage. in 2004 Annual Report Conference on Electrical Insulation and Dielectric Phenomena, 2004. CEIDP '04 332335 (2004).

[24] Singha, S. \& Thomas, M. J. Influence of filler loading on dielectric properties of epoxy-ZnO nanocomposites. IEEE Transactions on Dielectrics and Electrical Insulation 16, 531-542 (2009).

[25] Kochetov, R. et al. The effect of nanosilica on the DC breakdown strength of epoxy based nanocomposites. in 2014 IEEE Conference on Electrical Insulation and Dielectric Phenomena (CEIDP) 715-718 (2014).

[26] Tsekmes, I. A., Kochetov, R., Morshuis, P. H. F. \& Smit, J. J. AC breakdown strength of epoxy-boron nitride nanocomposites: Trend \& reproducibility. Electrical Insulation Conference (EIC), 446-449 (IEEE, 2015). 
[27] Preetha, P. \& Thomas, M. J. AC breakdown characteristics of epoxy alumina nanocomposites. in 2010 Annual Report Conference on Electrical Insulation and Dielectric Phenomena (CEIDP) 1-4 (2010).

[28] Tuncer, E. et al. Electrical properties of epoxy resin based nano-composites. Nanotechnology 18, 25703 (2007).

[29] Girard-Reydet E, Vicard V, Pascault JP, Sautereau H. Polyetherimide-modified epoxy networks: Influence of cure conditions on morphology and mechanical properties. J Appl Polym Sci 1997;65:2433-45.

[30] Riccardi, C. C. et al. Thermodynamic analysis of the phase separation in polyetherimide-modified epoxies. J. Polym. Sci. B Polym. Phys. 34, 349-356 (1996).

[31] Laurent, C. \& Teyssedre, G. Hot electron and partial-discharge induced aging of polymers. Nucl. Instr. and Meth. in Phys. Res. B 208, 442-447 (2003)

[32] Teyssedre, G., Berquez, L. \& Laurent, C. Some aspects of coupled electrical-mechanical effects in dielectric materials. Eur. Phys. J: Appl. Phys. 70, 20902-01/09 (2015)

[33] Personal communication: Halawani, N., Augé, J. L., Morel, H., Gain, O. \& Pruvost, S. Electrical, thermal and mechanical properties of poly-etherimide epoxy-diamine blend. Composites Part B: Engineering 110, 530-541 (2017)

[34] Gupta, D. K. D. \& Joyner, K. On the nature of absorption currents in polyethyleneterephthalate (PET). J. Phys. D: Appl. Phys. 9, 829 (1976).

[35] Jonscher, A. K. Frequency-dependence of conductivity in hopping systems. Journal of Non-Crystalline Solids 8, 293-315 (1972).

[36] Guillermin, C., Rain, P. \& Rowe, S. W. Transient and steady-state currents in epoxy resin. J. Phys. D: Appl. Phys. 39, 515 (2006).

[37] Mizutani, T. Space charge measurement techniques and space charge in polyethylene. IEEE Transactions on Dielectrics and Electrical Insulation 1, 923-933 (1994).

[38] O'Dwyer, J. J. The theory of electrical conduction and breakdown in solid dielectrics. (Clarendon Press, 1973).

[39] Alam, M. A., Azarian, M. H. \& Pecht, M. G. Modeling the Electrical Conduction in Epoxy-BaTiO3 Nanocomposites. Journal of Elec Materi 42, 1101-1107 (2013).

[40] Many, A. \& Rakavy, G. Theory of Transient Space-Charge-Limited Currents in Solids in the Presence of Trapping. Phys. Rev. 126, 1980-1988 (1962).

[41] Castellon J, Nguyen HN, Agnel S, Toureille A, Frechette M, Savoie S, et al. Electrical properties analysis of micro and nano composite epoxy resin materials. IEEE Transactions on Dielectrics and Electrical Insulation 2011;18:651-8.

[42] Krivda, A. et al. Characterization of epoxy microcomposite and nanocomposite materials for power engineering applications. IEEE Electrical Insulation Magazine 28, 38-51 (2012).

[43] Dissado, L. A. \& Fothergill, J. C. Electrical Degradation and Breakdown in Polymers. (IET, 1992).

[44] Dissado, L. A., Fothergill, J. C., Wolfe, S. V. \& Hill, R. M. Weibull Statistics in Dielectric Breakdown; Theoretical Basis, Applications and Implications. IEEE Transactions on Electrical Insulation EI-19, 227-233 (1984).

[45] Nascimento, E. do et al. Breakdown, free-volume and dielectric behavior of the nanodielectric coatings based on epoxy/metal oxides. J Mater Sci: Mater Electron 27, 9240-9254 (2016).

[46] Li B, Zhong W-H. Influence of Carbon Nanofiber Network Variability on the AC Conductivity of Polyetherimide Composite Films. Macromolecular Materials and Engineering 2010;295:310-4. doi:10.1002/mame.200900291.

[47] Chen G., Zhao J., Li S., Zhong L. Origin of thickness dependent de electrical breakdown in dielectrics. Appl. Phys. Lett. 100, 222904 (2012)

[48] Nelson, J. K. \& Fothergill, J. C. Internal charge behavior of nanocomposites. Nanotechnology 15, 586-595 (2004) 
List of Figure's captions:

Figure 11: Polarization current curves at $5 \mathrm{kV}$ for DM and DM10PEI

Figure 12: Absorption and depolarization currents under $5 \mathrm{kV}$ for a) DM and b) DM10PEI

Figure 13: Isochronal currents obtained from depolarization current

Figure 14: Conduction current density versus applied electric field

Figure 15: In (conductivity) versus $\sqrt{E}$ at room temperature: with $\sigma(\mathrm{S} / \mathrm{cm})$.

Figure 16: Representation of conduction data in a Fowler-Nordheim plot

Figure 17: J versus $\sqrt{E_{C}}$ for Schottky

Figure 18: a) TEM image of DM5PEI and b) AFM image of DM10PEI

Figure 19: Weibull distribution plot (95 \% confidence interval) for DM, PEI, DM5PEI and DM10PEI

Figure 20: SEM images of the breakdown channel in DM10PEI sample a) face view and b) side view after breaking the sample as illustrated in the schemas

\section{List of table Captions:}

Table 3: Obtained slopes of I-E curves from isochronal plots

Table 4: Scale and shape parameter from Weibull distribution 


\title{
Poly-etherimide epoxy diamine blends: Conductivity and breakdown voltage measurements at room temperature
}

\author{
N. Halawani ${ }^{1,2}$, J.L. Augé ${ }^{1}$, O. Gain ${ }^{2}$, V. Griseri ${ }^{3}$, G. Teyssèdre ${ }^{3}$ and S. Pruvost $^{2}$ \\ ${ }^{1}$ Univ Lyon, INSA Lyon, UMR CNRS 5005, AMPERE, F- 69622, Villeurbanne, F rance \\ ${ }^{2}$ Univ Lyon, INSA Lyon, UMR CNRS 5223, IMP Ingénierie des Matériaux Polymères, F-69621, Villeurbanne, France \\ ${ }^{3}$ LAPLACE (Laboratoire Plasma et Conversion d'Energie), Université de Toulouse, CNRS, UPS, INPT; Bat 3R3, 118, route de Narbonne, F- \\ 31062 cedex 9, France \\ *corresponding authors: jean-louis.auge@univ-lyon1.fr
}

Abstract - This paper presents an investigation on the current and breakdown voltage measurements in thermoset-thermoplastic blends based on an epoxy-amine/poly-etherimide phase separated material. Thermosetthermoplastic separated blends could be a novel material for insulation applications and can be compared to epoxy/inorganic composites systems. Pure epoxy network as well as the blends with $10 \mathrm{wt} \%$ of PEI were studied in terms of conduction and transient currents. An ohmic behavior below the threshold field $\left(\mathrm{E}_{\mathrm{th}}\right)$ and space-chargelimited conduction (SCLC) above $\mathrm{E}_{\mathrm{th}}$ are pointed out. Contact emission phenomenon was investigated by means of Schottky model and seems to be valid for both materials. The addition of 5 and 10 wt $\%$ of PEI into the epoxy system showed an increase in the values of breakdown voltage with the increase of the PEI amount.

Keywords: Epoxy; organic-organic blend; insulating material, electrical properties

\section{Introduction}

Epoxy resin is a common electrical insulating polymer, which is used in high voltage resin casted transformers, cable terminations and other accessories [1]-[4]. Epoxy composites and epoxy-thermoplastic blends are two types of material combination made of organic - inorganic and organic - organic mixture, respectively, where the epoxy is the major organic matrix in both situations. Both kinds of materials differ in their composition and thus in their characteristics and applications. Epoxy/filler composites are extensively investigated to observe the influence of the fillers on different properties of the epoxy network and precisely the thermal and electrical ones [5][8]. The studies can be classified depending on the size of the filler used, being micro-sized, nano-sized or a combination of both micro and nano-sized fillers. Moreover, polymer blends and especially epoxy/thermoplastic blends are also extensively studied to show the influence of incorporating a thermoplastic on the mechanical, thermal and solvent resistance properties of the epoxy network [9]- [12].

Epoxy/inorganic composites, with nano and micro sized fillers, have shown mechanical and thermal improvement and have gained more attention in many applications. The addition of these kinds of fillers in the formulation improves for example fire resistance [5],[7],[13],[14]. Khan et al. showed how the mechanical properties of an 
epoxy matrix can be improved with the incorporation of ceramic nanoparticles [15]. During the last decade, some extensive researches were performed to improve the fracture toughness of epoxies with the addition of inorganic fillers, showing an increase in the tensile and young's modulus and the glass transition temperatures [16]-[18].

Electrical properties were more specifically investigated in epoxy composites. Breakdown voltage tests were performed and presented a decrease in the values with the increase of the percentage of micro-particles as shown in several studies [19]-[21]. In general, the incorporation of micro-fillers into an epoxy network leads to a decrease of the breakdown voltage value with respect to pure epoxy and to an increase of the dielectric permittivity values. These micro-composites are good candidates for mechanical achievements as well as for thermal exchange purpose. However; they are not suitable to enhance the dielectric strength of an epoxy network needed for insulations in the high voltage industry.

Over the last decade, the interest in the use of nano-sized fillers as additives to polymer materials (nanocomposites) and specifically in epoxy based materials has increased. An essential criterion in the preparation of this type of material is the dispersion quality of the nanofillers in the epoxy network. Many families of nanofillers were studied, such as silica, alumina, titania, zinc-oxide, barium nitrate, barium titanate and many more used in different nano sizes with or without surface modification. On one hand, some researchers reported an increase of the breakdown values below small critical percentages [6], [22]-[26]. On the other hand, different studies using different percentages and different nanoparticles sizes showed a decrease in the dielectric breakdown of nano-composites in comparison with the neat epoxy network even at low weight fraction. In such cases, the explanation provided is the lack of adhesion at the interface between the epoxy network and the fillers [21],[26]-[28].

Conflicting results on the performance of nanocomposite fillers have been reported and the underlying mechanisms are not sufficiently understood. Several factors can interfere with the incorporation of nanoparticles in the epoxy network on its electrical properties. In order to increase the breakdown voltage value or decrease the permittivity values, the nanoparticles should be relatively small $(<50 \mathrm{~nm})$ and should be functionalized to control the filler/epoxy matrix interface. Otherwise the fillers will act as defects. Adequate surface modification of the fillers improves the interface between the nanoparticles and the epoxy matrix and their dispersion avoiding aggregation or voids formation. Last but not least the content of nanoparticles should not exceed a critical small fraction value above which aggregates can be formed.

In this present work, the studied material is a thermoset/thermoplastic blend having a phase separation phenomenon. This kind of blend is different from the epoxy/inorganic composites as the obtained nodules are formed from an organic material. Some of thermoset/thermoplastic blends are known to enhance the mechanical 
properties of the thermoset network [29],[30]. The thermoplastic nodules act as obstacles absorbing the propagation of cracks and thus increasing the mechanical strength of the blend. From this particular point, an idea was built to study the influence of the phase-separated nodules on the voltage breakdown, the underlying assumption being that the propagation of cracks from mechanical excitation may have similar mechanism as electrical breakdown. Indeed, the different stages of electrical ageing of solid insulation according to the well-accepted model within the dielectric community contain mechanical processes [31],[32]. The electromechanical properties are involved along the ageing process and control, partly or totally, the initial stages with nano-voids formation as well as the final stage of electrical treeing propagation. The thermal, mechanical and dielectric properties of the proposed epoxy/thermoplastic blend were demonstrated in a previous study [33]. Current measurements as well as breakdown voltage measurements are presented in this work.

\section{Experimental}

\section{II.1. Materials}

The epoxy prepolymer used was Diglycidyl ether of bisphenol A, liquid at room temperature, $D G E B A_{\bar{n}=0.15}$ (Araldite LY556 from Huntsman). The curing agent was an aromatic diamine, 4,4'-methylenebis-[2,6diethylaniline], M-DEA supplied by Lonzacure ${ }^{\mathrm{TM}}$. The diamine was added in the stoichiometric ratio, epoxy to amine hydrogen groups equal to 1 , in pure and modified mixtures. The thermoplastic used was Polyetherimide, PEI Ultem 1010, supplied by General electric. The preparation protocol of the pure epoxy network as well as the blend of epoxy and PEI is explained in a previous work [33].

For the designation of the systems, the term DM corresponds to the epoxy-amine (DGEBA-MDEA) system without thermoplastic, which is also called neat network, and DM5PEI and DM10PEI denotes the system DGEBA-MDEA modified with 5 wt.\% and 10 wt.\% of PEI respectively.

\section{II.2. Techniques}

\section{II.2.1. Current measurements}

Samples were processed in disk form of $6 \mathrm{~cm}$ diameter and of thickness between 0.5 and $1 \mathrm{~mm}$. Gold electrodes of 4 $\mathrm{cm}$ in diameter were deposited using a cool sputter coater model SCD 005 from BAL-TEC. An elastomer was laid out at the periphery of the gold electrodes to increase the path between the electrodes (high voltage and ground) and mitigate the influence of the edge of the metallization where the electric field is out of control. The external current was recorded by means of a Keithley 6512 ammeter. Preliminary measurement with elastomer and a guard electrode 
carried out under high vacuum $\left(<10^{-4} \mathrm{~Pa}\right)$ to eliminate spurious currents such as partial discharges and leakage current at the surface of the sample was performed. Results obtained under vacuum or not are the same for the range of voltage investigated (up to $20 \mathrm{kV} \mathrm{DC}$ ).

Each DC electric field step was applied to the sample for 1 hour before the film was put under short-circuit conditions for the same duration at room temperature $\left(21^{\circ} \mathrm{C}\right)$. The same polarization and depolarization procedure was repeated for increasing values of the applied field $\left(1.6,5,8.3,11.6,16.6\right.$ and $\left.25 \mathrm{kV} . \mathrm{mm}^{-1}\right)$. The current was measured continuously along the whole stress cycle in steps of $2 \mathrm{~s}$.

\section{II.2.2. Breakdown Voltage measurements}

Breakdown strength of the samples was measured by applying a linearly increasing DC voltage $(2 \mathrm{kV} / \mathrm{s}) \mathrm{up}$ till the breakdown takes place. The sample of $6 \mathrm{~cm}$ diameter and a thickness between $300 \mu \mathrm{m}$ and $700 \mu \mathrm{m}$ is placed between two steel spherical electrodes $18 \mathrm{~mm}$ in diameter. The whole assembly is immersed in insulating silicon oil to avoid discharges.

\section{II.2.3. Microstructure analysis}

Transmission Electron Microscopy (TEM) analysis was performed on Philips CM120 transmission electron microscope (at the Centre Technologique des Microstructures CT $\mu$ of the University of Lyon) with an accelerating voltage of $80 \mathrm{kV}$. Epoxy samples were trimmed using an ultra-microtome and the slices (60-70 $\mathrm{nm}$ in thickness) were placed onto 300 mesh copper grids for observation.

Atomic Force Microscopy (AFM) images were collected in tapping mode using an AFM Bruker Multimode 8 equipped with Nanoscope V controller. The scanning speed for image acquisition was $0.5 \mathrm{~Hz}$. The used cantilevers are Bruker TAP 150A with a radius of curvature of the tip of $8 \mathrm{~nm}$. Samples used for analysis were trimmed using an ultra-microtome to obtain a smooth surface.

\section{Results and Discussions}

\section{III.1. Transient Currents}

The recorded current, under $5 \mathrm{kV}$ voltage representing a field of $8.3 \mathrm{kV} / \mathrm{mm}$, with respect to time is presented in Figure 1. The polarization current $I_{P}$ follows a transient regime and then stabilizes in both DM and DM10PEI. The quasi-steady-state charging current obtained after $1 \mathrm{~h}$ is taken as the conduction current $\mathrm{I}_{\mathrm{C}}$. The difference between the charging current and the conduction current is the absorption current $\mathrm{I}_{\mathrm{a}}$. Current values were influenced by the presence of PEI in the epoxy network showing higher values for DM10PEI compared to the pure DM sample. Similar features were observed upon applying different voltages starting from 1 up to $15 \mathrm{kV}$. 


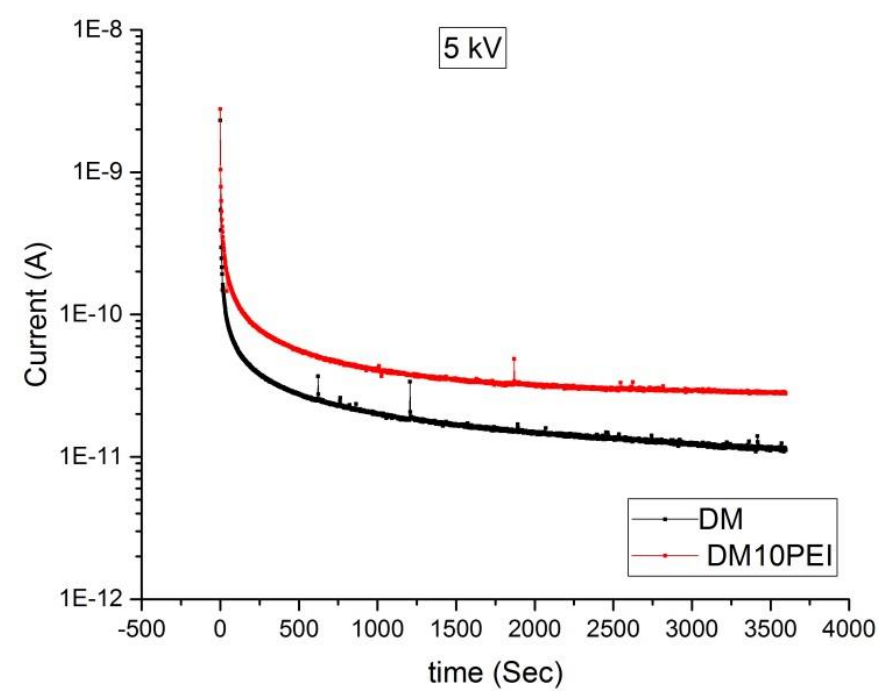

Figure 1: Polarization current curves at $5 \mathrm{kV}$ for DM and DM10PEI

Figure 2 presents a comparison between the absorption currents and the depolarization currents of both DM and DM10PEI. The results are shown for a voltage of $5 \mathrm{kV}$. Similar responses were obtained with all the tested electric fields that is to say the absorption and the depolarization currents followed the same evolution with respect to time and under the same applied electric field. The negative slope of the absorption and discharging currents for DM was measured between $10 \mathrm{~s}$ to $700 \mathrm{~s}$ and found to have the same value of 0.68 . DM10PEI showed similar reversibility, with a slope of 0.65 , for the two responses between $10 \mathrm{~s}$ and $600 \mathrm{~s}$ above which the absorption response starts to decay. This reversibility shows that the polarization phenomenon in this case is dominated by the dipolar movements and is not affected by space charge phenomena [34].
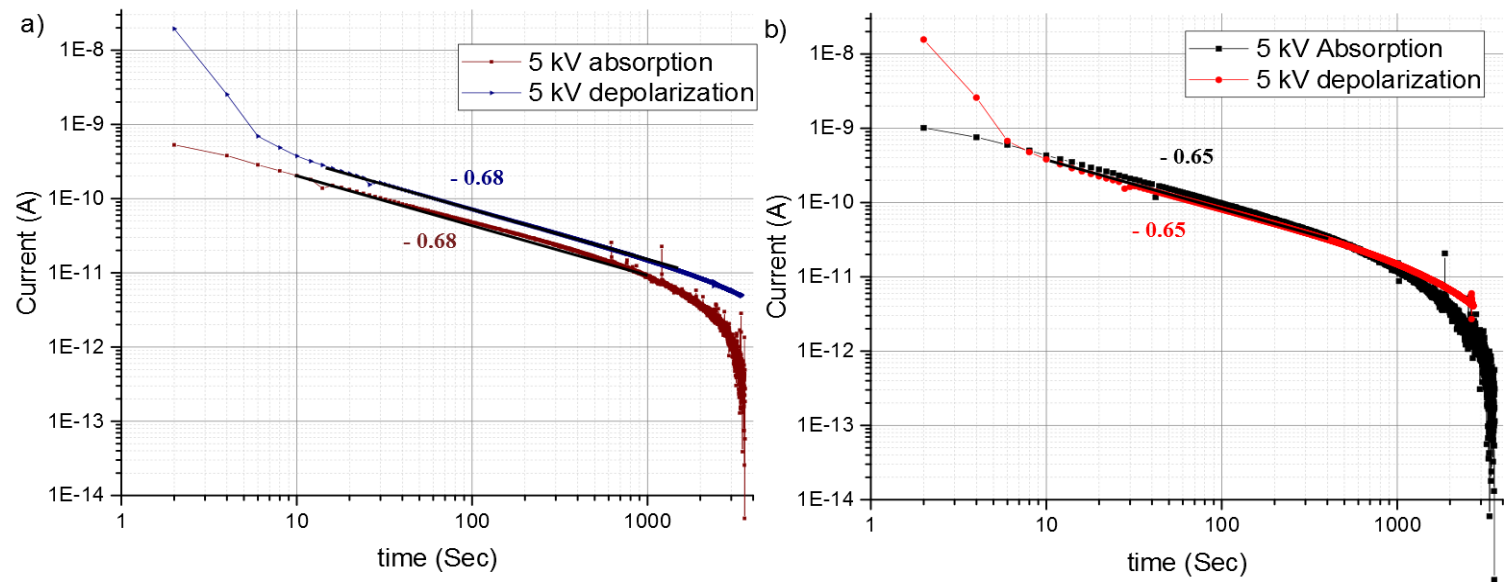

Figure 2: Absorption and depolarization currents under $5 \mathrm{kV}$ for a) DM and b) DM10PEI

The measured currents show obvious dependence with time (t) and applied electric field (E). The transient current has been observed to decay following the well-known Curie law [34]: 


$$
I(t)=k \cdot E \cdot t^{-n}
$$

Eq. 1

where $\mathrm{k}$ is a constant that depends on temperature and $\mathrm{n}$ is dependent of the material and can be obtained from the slope between I and $\mathrm{E}$ in isochronal plot. The dependence of isochronal current with respect to applied electric field at different times is shown in Figure 3 and the obtained slopes are extracted in Table 1.

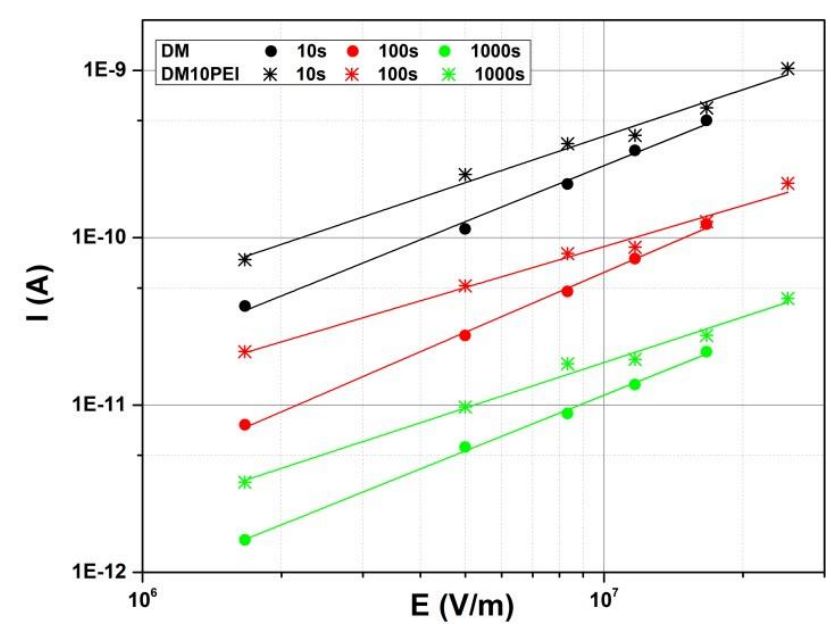

Figure 3: Isochronal currents obtained from depolarization current

Table 1: Obtained slopes of I-E curves from isochronal plots

\begin{tabular}{|c|c|c|c|}
\hline Time (s) & 10 & 100 & 1000 \\
\hline DM & 1.1 & 1.19 & 1.1 \\
\hline DM10PEI & 0.93 & 0.87 & 0.9 \\
\hline
\end{tabular}

The plots of the isochronal discharging currents at 10,100 and 1000 attest the proportionality of the discharging currents to the applied field. The slope varies by less than $9 \%$ and $6 \%$ respectively for DM and DM10PEI with respect to time. The slopes are in the same range, being slightly higher for the pure resin. The obtained slopes for DM can be referred to electrode polarization, dipolar orientation, tunneling and hopping effect [35]. With the addition of PEI the slopes decrease below 1 suggesting the same phenomena as DM. On the other hand, Guillermin et al. suggested in a similar studied material that the decrease of the slope below 1 presents charge injection leading to trapped space charge effects [34], [36],[37]. As this phenomenon was not demonstrated in the reversibility curves, space charge measurements should be experimented to prove it.

\section{III.2. Conduction currents}

An estimation of the conduction current for each applied voltage was carried out from the average of the current measured within the last $20 \mathrm{~s}$ in the quasi-steady-state. Current densities $\mathrm{J}\left(\mathrm{A} / \mathrm{m}^{2}\right)$ at room temperature are plotted in $\log -\log$ scale as function of the applied electric field $\mathrm{E}(\mathrm{kV} / \mathrm{mm})$ for DM and DM10PEI in Figure 4. The two curves present two different conduction modes separated by a threshold field $\mathrm{E}_{\mathrm{th}}$. Below this threshold, both pure epoxy 
DM and DM10PEI have a linear relation between $\mathrm{J}$ and $\mathrm{E}$ with a unit slope corresponding to the Ohmic conduction phenomenon. The threshold field for the blend $(9.2 \mathrm{kV} / \mathrm{mm})$ was lower than that of DM $(12.5 \mathrm{kV} / \mathrm{mm})$ by about 25 $\%$. The presence of PEI might reduce the voltage range of the ohmic regime. This decrease in the threshold field can be an advantage in some applications such as using the epoxy for cable junction.

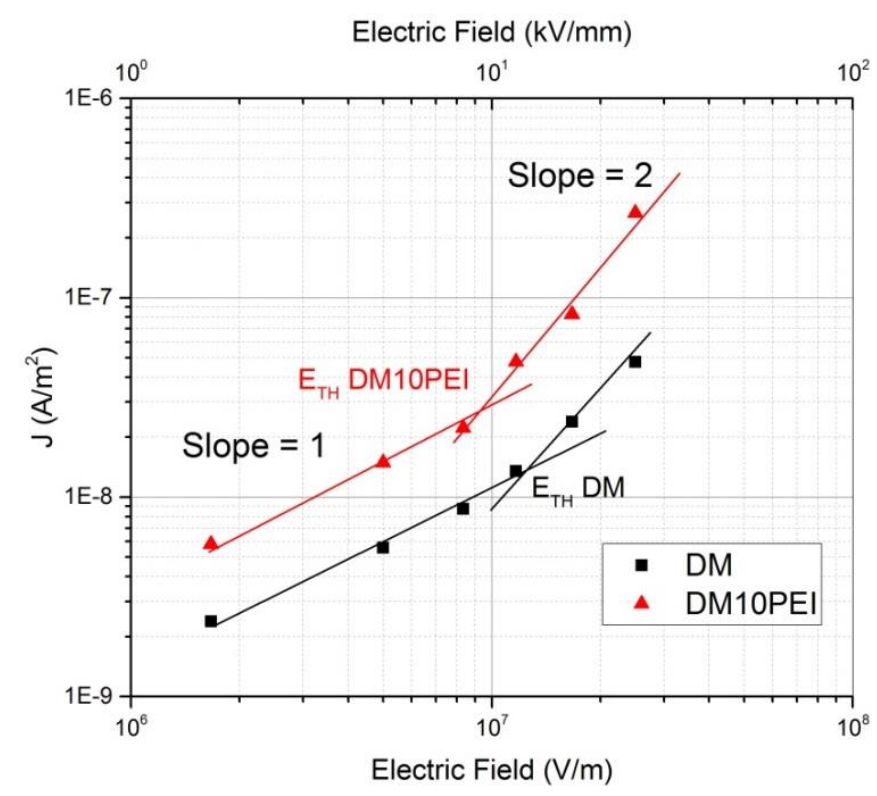

Figure 4: Conduction current density versus applied electric field

Above the threshold field, a non-linearity in the conduction current appears for both samples with a slope of 2 . Similar phenomenon for pure epoxy network with anhydride hardener was obtained with a higher threshold field of $17 \mathrm{kV} \cdot \mathrm{mm}^{-1}$ [36]. The type of hardener has an impact on the matrix structure and the cross-linking ratio and by this way on the motion of the charge carriers.

The conduction phenomenon is dependent on the charge injection behavior as well as the volume conduction behavior. In the following part, both behaviors will be discussed, exploring the Poole-Frenkel mechanism and spacecharge-limited conduction (SCLC) model for the volume conduction phenomenon and the Fowler-Nordheim effect and the Schottky effect to deduce the charge injection mechanism.

\section{III.3. Analysis of conduction process}

\section{III.3.1. Volume-limited conduction}

\section{III.3.1.1 Poole-Frenkel mechanism}

In the Poole-Frenkel mechanism, electrons are trapped in localized states where upon applying either sufficient temperature or high voltage they move to the conduction band and freely in the material. The conductivity in such case obeys the following equation: 


$$
\sigma=\sigma_{0} \exp \left(\frac{\beta_{P F} \sqrt{E}}{k_{B} T}\right)
$$

Eq. 2

where $\mathrm{k}_{\mathrm{B}}$ is the Boltzmann's constant, $\mathrm{T}$ the temperature and $\beta_{\mathrm{PF}}$ the Poole-Frenkel constant [38]. This latter depends on the relative permittivity of the material and follows this law:

$$
\beta_{P F}=\left(\frac{q^{3}}{\pi \varepsilon_{0} \varepsilon_{r}}\right)^{1 / 2}
$$

where $\mathrm{q}$ is the elementary charge, $\varepsilon_{0}$ the vacuum permittivity, $\varepsilon_{\mathrm{r}}$ the relative permittivity of the tested material.

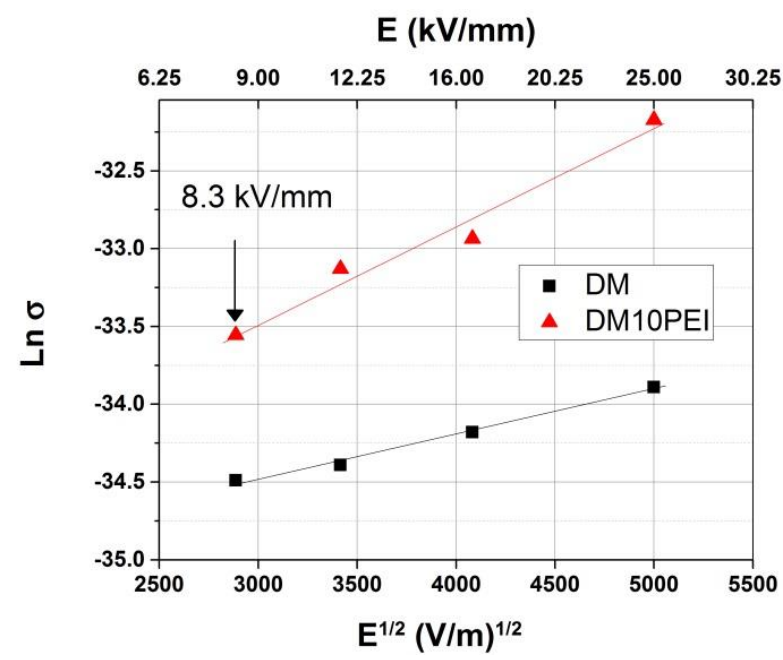

Figure 5: In (conductivity) versus $\sqrt{ } \mathbf{E}$ at room temperature: with $\sigma(\mathrm{S} / \mathrm{cm})$.

Poole Frenkel conduction phenomenon was checked by plotting $\ln \sigma$ versus $\sqrt{E}$ as shown in Figure 5. To fit this law, from Eq. 2 and Figure 5, $\beta_{\mathrm{PF}}$ is calculated from the value of the slope $\left(\beta_{\mathrm{PF}} / \mathrm{k}_{\mathrm{B}} \mathrm{T}\right)$. Its value is equal to $1.2 \times 10^{-24}$ and $2.6 \times 10^{-24} \mathrm{~J} \cdot \mathrm{m}^{-1 / 2} \cdot \mathrm{V}^{-1 / 2}$ for DM and DM10PEI respectively. Calculating $\beta_{\mathrm{PF}}$ theoretically from Eq. 3, the obtained values are $5.33 \times 10^{-24}$ and $5.58 \times 10^{-24} \mathrm{~J} \cdot \mathrm{m}^{-1 / 2} \cdot \mathrm{V}^{-1 / 2}$ for DM and DM10PEI respectively. The values were obtained using the relative permittivity taken from the dielectric measurements at $25{ }^{\circ} \mathrm{C}$ and $1 \mathrm{MHz}\left(\right.$ for $\mathrm{DM} \varepsilon_{\mathrm{r}}=$ 5.17 and for DM10PEI $\varepsilon_{\mathrm{r}}=4.73$ ) [33]. The gap between experimental value of $\beta_{\mathrm{PF}}$ and the calculated one varies by 50-70\%. Thus the conductivity seems not controlled by the Poole-Frenkel law. A similar conclusion was reached when pure epoxy network was measured below its glass transition temperature [39]. This law was only confirmed when the temperature was above the glass transition temperature of epoxy [36]

\section{III.3.1.2 Space-charge-limited conduction model (SCLC)}

Above the threshold field, a non-linearity in the conduction current appears for both samples with a slope of 2 . When the slope is equal to 2 the volume conduction phenomenon fits well with the space-charge-limited conduction model (SCLC). The current density (J) in this case is described by [40]: 


$$
J=\frac{9 \varepsilon_{r} \varepsilon_{0} \mu V^{2}}{8 d^{3}}
$$

Eq. 4

where $\mu$ is the carrier mobility and $d$ is the thickness of the sample.

From the dielectric measurements it was noticed that below $0.1 \mathrm{~Hz}$, no modification of the permittivity was measured, and it was supposed to be under DC condition [33]. The carrier mobility $\mu$ at $10 \mathrm{kV}$ (field of 16kV/mm) is $8.1 \times 10^{-10}$ and $2 \times 10^{-9} \mathrm{~cm}^{2} \mathrm{~V}^{-1} \mathrm{~s}^{-1}$ for DM and DM10PEI respectively. The difference in mobility between the two systems is not significant. These values are in the same range of what is found in the literature for pure epoxy networks in this field range such as $2.3 \times 10^{-10} \mathrm{~cm}^{2} \mathrm{~V}^{-1} \mathrm{~s}^{-1}[36], 1.5 \times 10^{-10} \mathrm{~cm}^{2} \mathrm{~V}^{-1} \mathrm{~s}^{-1}$ [41] and between $10^{-9}$ and $10^{-10}$ $\mathrm{V}^{-1} \mathrm{~s}^{-1}[42]$

\section{III.3.2. Injection-controlled current}

The conduction currents could be controlled by the interface present between the electrode and the sample by the Fowler-Nordheim effect (electron tunneling through an exact or rounded triangular barrier) or the Schottky (jump above the potential barrier). The latter appears generally at high fields or very low temperatures.

\section{III.3.2.1. Fowler-Nordheim}

Fowler-Nordheim model adopts the injection of electrons at the metal-dielectric interface [43]. It is verified by presenting $\ln \frac{\mathrm{J}}{\mathrm{E}^{2}}$ in function of $\frac{1}{\mathrm{E}}$ as shown in Figure 6. This representation did not show a straight line in both pure epoxy and the blend. Therefore the Fowler-Nordheim is not applicable in the studied case. This is an expected fact since Fowler-Nordheim process requires higher electric fields. The injection by tunneling effect through the potential barrier is to be discarded.

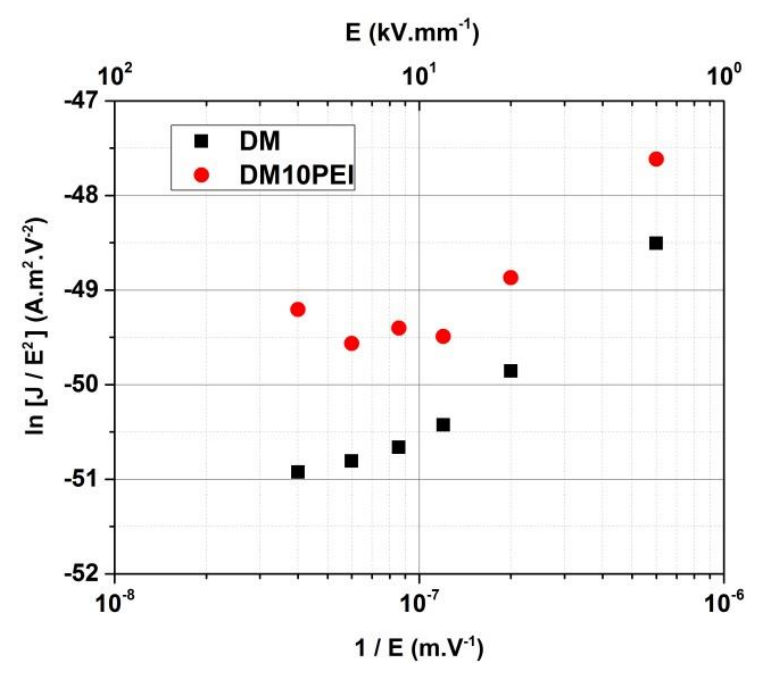

Figure 6: Representation of conduction data in a Fowler-Nordheim plot 


\section{III.3.2.2. Schottky effect}

The current density emitted due to Schottky effect can be described as:

$$
J_{s}=A_{s} T^{2} \exp \left(-\frac{\Phi_{0}-\beta_{s} \sqrt{E_{c}}}{k_{B} T}\right)
$$

Eq. 5

where, $A_{s}$ is the Richardson-Dushman constant for thermionic emission and $E_{c}$ the field at the cathode. $\beta_{s}$ is the Schottky constant:

$$
\beta_{s}=\sqrt{\frac{q^{3}}{4 \pi \varepsilon_{0} \varepsilon_{r}}}
$$

Eq. 6

A plot of $\ln \left(\mathrm{J}_{\mathrm{s}}\right)$ versus $\sqrt{E_{C}}$ is presented in Figure 7.

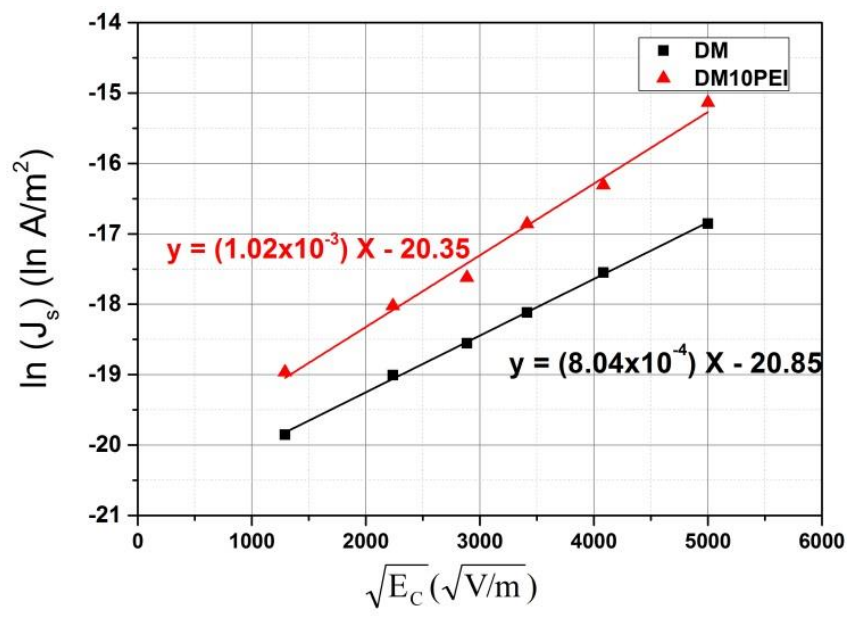

Figure 7: J versus $\sqrt{E_{C}}$ for Schottky

From the obtained slope we can calculate the relative permittivity and compare it with the obtained values from the dielectric measurements using the following equation:

$$
\text { slope }=\frac{\beta_{S}}{k_{B} T}=\frac{1}{k_{B} T} \cdot \sqrt{\frac{q^{3}}{4 \pi \varepsilon_{0} \varepsilon_{r}}}
$$

The obtained values of $\varepsilon_{\mathrm{r}}$ are 3.37 and 2.1 for DM and DM10PEI respectively, which are different from the measured values. It can be argued that the electric field at the cathode is not the average field as it might be modified by trapped space charges. To account of space charge effects, one can consider that there is a distortion of field by introducing a dimensionless alpha parameter:

$$
E_{C}=\alpha \frac{V}{d}
$$

Eq. 8

with $\alpha<1$ for a homocharges dominant at contact and $\alpha>1$ if heterocharges dominate. The field at the cathode is decreased with the existence of homocharges while it is increased if the heterocharges accumulate close to the electrode. The expression of the Schottky current becomes: 


$$
J_{s}=A_{s} T^{2} \exp \left(-\frac{\Phi_{0}-\beta_{s} \sqrt{\alpha \frac{V}{d}}}{k_{B} T}\right)
$$

Eq. 9

The parameter $\alpha$ can now be calculated from the slope obtained using the following equation:

$$
\alpha=\frac{(\text { slope })^{2}\left(k_{B} T\right)^{2} 4 \pi \varepsilon_{0} \varepsilon_{r}}{q^{3}}
$$

Current densities of both DM and DM10PEI are proportional to $\sqrt{\mathrm{E}}$ with slopes in the same range. The calculated values of $\alpha$ are 1.53 and 2.25 for DM and DM10PEI respectively. As the values of $\alpha$ are higher than 1 this would imply that the heterocharges near the cathode increase the local field and tend to decrease the energy barrier at the electrode-polymer interface. With the addition of PEI the injection field at the cathode is increased in comparison with the neat epoxy. Our value of $\alpha$ for the neat epoxy is less than the one reported by [41] evaluated at 2.55 . The Schottky emission process cannot be discarded in this approach where the value of $\alpha$ would increase with the addition of PEI to the pure epoxy network. However, the estimation is dependent on the material in contact with the electrode. It may be possible that an epoxy layer be present at the surface of films, hence the permittivity to be considered for the interface may not be the average one for the polymer blend.

\section{III.4. Breakdown Voltage}

Breakdown voltage provides the probable maximum voltage that a material can withstand before breaking down. For mechanical applications, it was found that introduction of PEI nodules in the epoxy enhances the withstanding of the epoxy. For example, nodules can attenuate mechanical cracks propagation [29]. Starting from this idea of having nodules of PEI, and hypothesizing that this structuration could enhance dielectric strength as well, blends were made using to $5 \mathrm{wt} \%$ and $10 \mathrm{wt} \%$ of PEI for which structures with nodules were made. Figure 8 gives an example for the microstructure of DM5PEI, noting that more complete characterization was presented previously [33]. Besides, PEI has lower relative dielectric values that decreased the permittivity of the blend with respect to that of pure epoxy DM [33].

\section{III.4.1.Morphology}

The structure analysis of the epoxy blends was performed using transmission electron microscopy (TEM) and Atomic Force Microscopy (AFM). In the TEM image of DM5PEI, Figure 8 (a), the dark part corresponds to the PEI nodules and the bright and continuous phase corresponds to the epoxy network. Figure 8 (a) confirms a relatively homogeneous distribution of the PEI nodules in the epoxy network in the blend. The nodules have an ellipse shape in the blend, with the main diameter between $0.5-2 \mu \mathrm{m}$. The AFM image, Figure 8 (b), of a single nodule confirms 
what is observed by means of TEM. An isolated PEI nodule in a DM10PEI sample is shown. It has a major diameter of $1.8 \mu \mathrm{m}$ and a minor diameter of $1.2 \mu \mathrm{m}$.
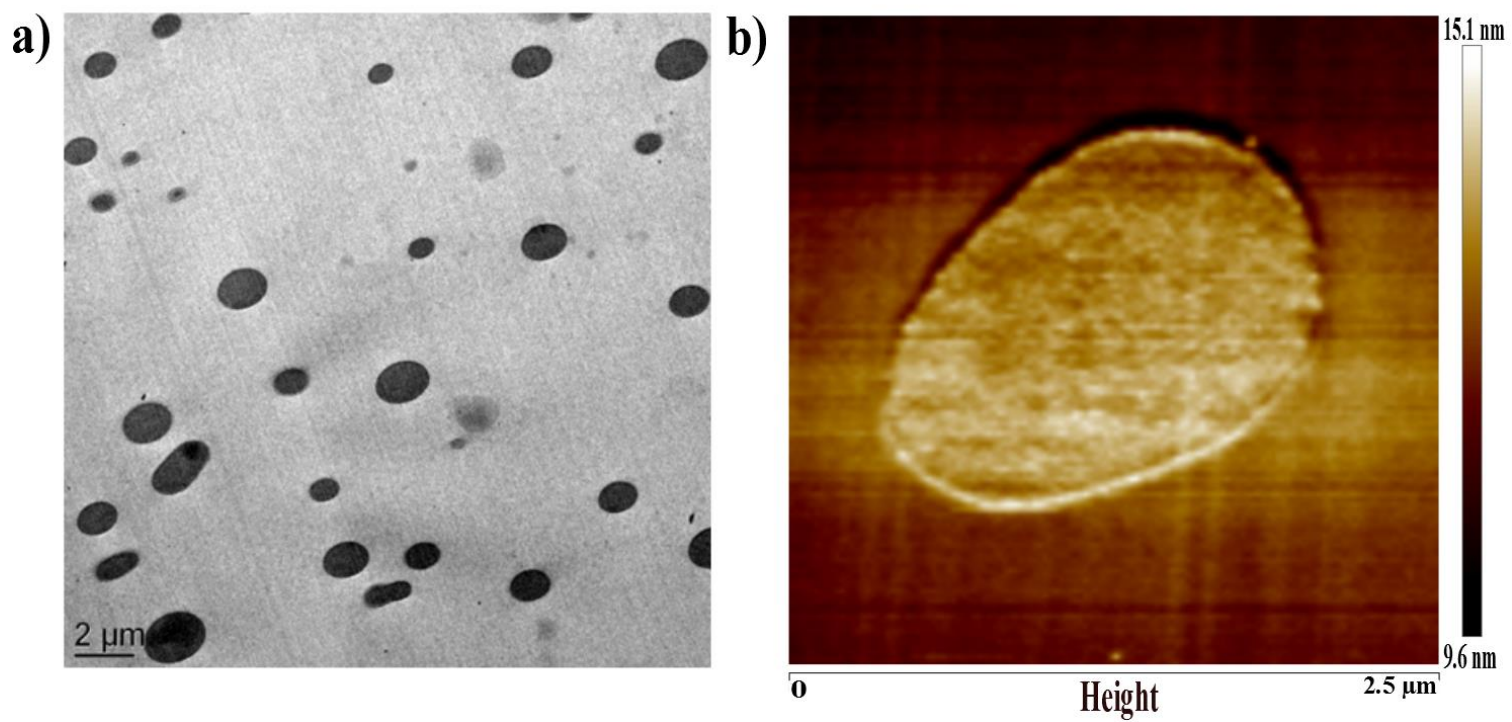

Figure 8: a) TEM image of DM5PEI and b) AFM image of DM10PEI

\section{III.4.2. Weibull Distribution Plot}

The Weibull distribution is the most common failure distribution for electrical breakdown [44]. The values of breakdown voltage were analyzed using the two-parameter Weibull statistical function. Measurements were carried out on a minimum of 10 samples for each system. Two parameters $\alpha$ and $\beta$ can be extracted from the Weibull distribution formula:

$$
\mathrm{F}(\mathrm{x})=1-\exp \left[-(\mathrm{x} / \alpha)^{\beta}\right], \mathrm{x}>0
$$

where $\mathrm{x}$ is the measured breakdown voltage, $\mathrm{F}(\mathrm{x})$ is the cumulative probability, $\alpha$ is the scale parameter and $\beta$ the shape parameter. In the represented graphs, the experimental values are plotted with different percentages using Weibull formula, where all the points are situated in an interval of $95 \%$ of confidence. $\alpha$ and $\beta$ can be deduced from the slope of the probability of breakdown line, where $\alpha$ is the breakdown voltage value at $63.2 \%$ of the probability distribution. Weibull distribution plots of DM, PEI, DM5PEI and DM10PEI are presented in Figure 9 and the corresponding parameters are collected in Table 2. 


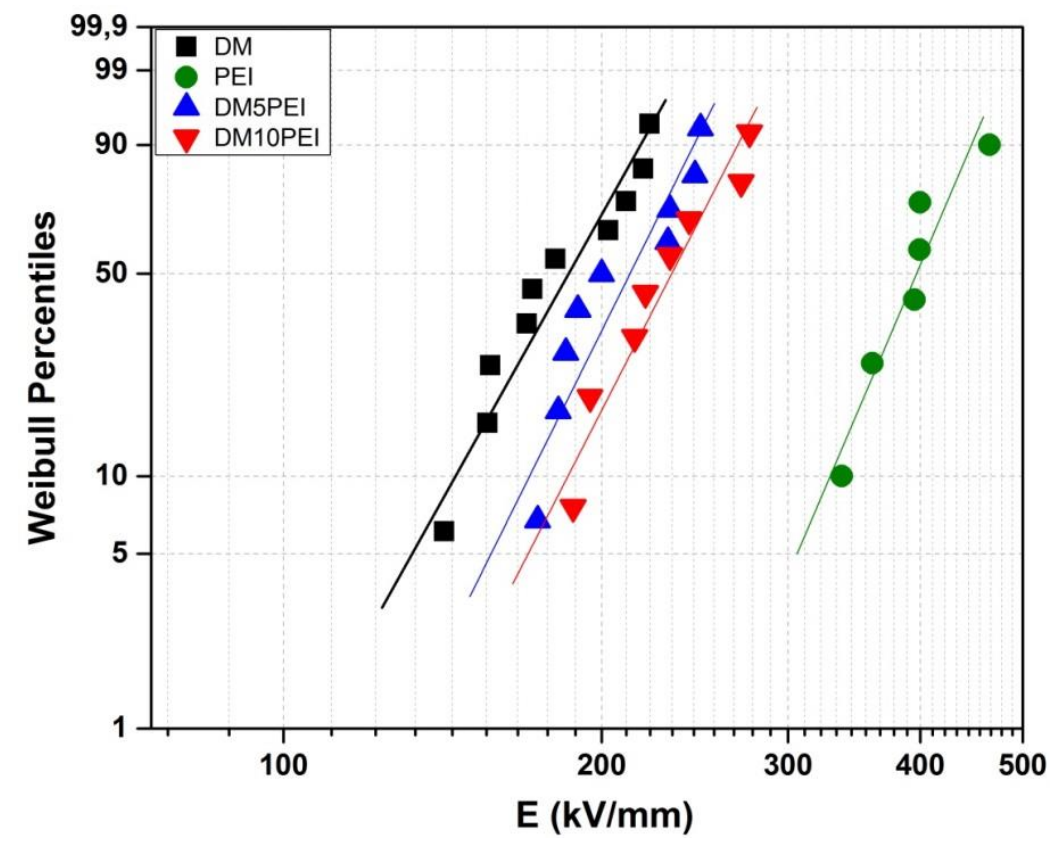

Figure 9: Weibull distribution plot (95 \% confidence interval) for DM, PEI, DM5PEI and DM10PEI

Table 2: Scale and shape parameter from Weibull distribution

\begin{tabular}{|c|c|c|c|}
\hline Sample & Shape parameter: $\boldsymbol{\beta}$ & $\begin{array}{c}\text { Scale parameter: } \boldsymbol{\alpha} \\
(\mathbf{k V / m m})\end{array}$ & \begin{tabular}{c} 
\% with respect to DM \\
\hline DM
\end{tabular} \\
\hline PEI & 7.6 & 195 & - \\
\hline DM5PEI & 10 & 412 & $\nearrow 14 \%$ \\
\hline DM10PEI & 8.6 & 222 & $725 \%$ \\
\hline
\end{tabular}

The scale parameter $\alpha$ for DM is equal to $195 \mathrm{kV} \cdot \mathrm{mm}^{-1}$; this value for a DC test is higher than the majority of breakdown tests on different systems of epoxy and hardeners. The published values for pure epoxy networks vary from 40 to $100 \mathrm{kV} \cdot \mathrm{mm}^{-1}$ [6], [21], [24], [27],[28],[45] Nevertheless, we have to mention that the common used technique for such characterization is an AC breakdown test, where the values are expected to be lower due to fatigue and energy dissipation. AC breakdown tests will be examined in a future work. PEI demonstrated a higher breakdown voltage $\alpha$ of $412 \mathrm{kV} / \mathrm{mm}$. Blending epoxy with $5 \mathrm{wt} \%$ of PEI has increased the breakdown voltage of the epoxy system by $14 \%$ while when increasing the fraction of PEI to $10 \mathrm{wt} \%$ a gain of $25 \%$ in dielectric strength is possible. The results obtained with the incorporation of nodules confirm the idea of resistance to micro cracks that tend to propagate during a breakdown process. This gives the whole system the ability to withstand higher applied fields. 
Figure 10 shows SEM images of the void tunnel formed in the bulk of the sample due to the electrical breakdown test. The samples are seen from the face and from cross section after breaking the sample in the middle of the hole present after the test. The hole has a circular shape with a diameter in the range 430 to $460 \mu \mathrm{m}$. The hole is narrower in the bulk as seen in Figure 10 (b). The size of the produced hole after the breakdown test is similar to that reported in other studies, such as the work of Iyer et al. on epoxy/inorganic micro-composites [6]. In the sphere-sphere configuration, a quasi-homogeneous field exists at the electrode-dielectric interfaces. The damage could thus equally initiate anywhere within the structure, and should hence first take place in the vicinity of major defects. As a result, it is not possible in this electrode configuration to identify a unique starting point and an end to the damage propagation.
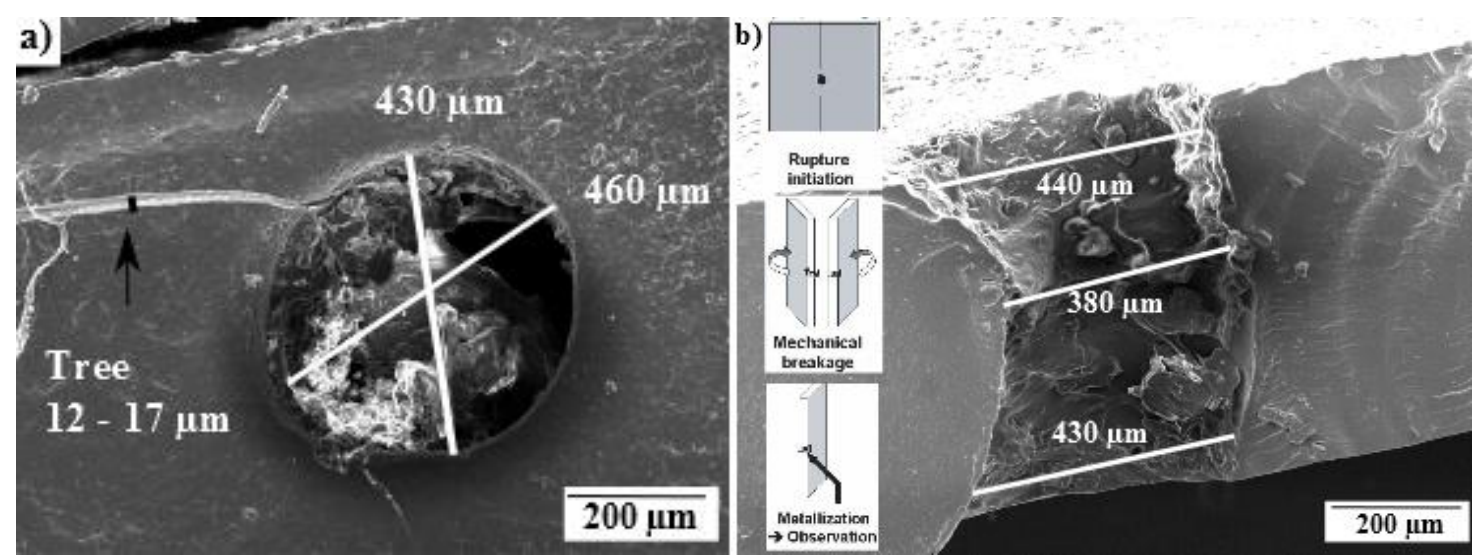

Figure 10: SEM images of the breakdown channel in DM10PEI sample a) face view and b) side view after breaking the sample as illustrated in the schemas

\section{Discussion}

The results obtained can be summed-up as follows. The blends are constituted of an epoxy matrix with PEI nodules of about $1 \mu \mathrm{m}$ side dispersed relatively homogenously in the matrix. A significant increase of the breakdown field is obtained when incorporating 5 wt. \% $(+14 \%)$ or 10 wt. \% (+25\%) of PEI nodules. It must be noted here that unlike what can be observed when dispersing nanoparticles into a polymeric matrix, there is no 'optimum' concentration of the compound at low concentration. This is probably due to the good quality of the dispersion obtained in the current blend, ensured by the separation via a spinodal decomposition mechanism contrary to a nucleation and growth mechanism, compared to the difficulty in maintaining the quality of dispersion of nanoparticles at high concentration.

The increase in the breakdown strength has to be put in relation with values of relatively permittivity for the epoxy (6.4) and of 10 wt. \% blend (5.8) at $0.1 \mathrm{~Hz}$ and with conductivity: conductivity is higher in PEI-containing samples. Anticipating that the permittivity in PEI is lower than that of epoxy, and that the conductivity in PEI is in similar 
range as epoxy [46], these features would lead to field intensification in PEI under AC stress (capacitive distribution). As for under DC measurements (resistive distribution), space charge measurements is needed to provide more explanation. However, internal interfaces in the matrix may provide a more complex behavior than expected. The last information brought by the results is on the possible transport mechanism: conduction would be controlled by SCLC process or by Schottky law supposing that substantial field intensification occurs at the electrodes. So far, to our knowledge, there is no report on space charge measurements in epoxies demonstrating huge heterocharge accumulation. Therefore the SCLC mechanism is privileged. It must be stressed here that SCLC in its strict formulation including ohmic contact and unipolar transport is probably not at play either. In fact most of models combining current limitation at the interface and transport with trapping tend to show a non-linear behavior in a given field range.

Extrapolating transport properties obtained at fields up to $25 \mathrm{kV} / \mathrm{mm}$ up to the breakdown field range which is one order of magnitude higher is questionable. However, the possible reason for the improvement in the breakdown strength could be as follows. G Chen et al. [47] proposed a unified model of transport and breakdown in polyethylene under DC stress supposing that a critical field exists as an intrinsic property of the material, of the order of $400 \mathrm{kV} / \mathrm{mm}$ for PE. If the field exceeds locally this critical value, the breakdown occurs. Space charge build up can be an influential factor in reaching the critical field. So, for the present studied case, the critical field would be related to the epoxy matrix, since according to breakdown strength results, it represents a priori the weak point in the composite. The higher conductivity obtained in the blend could attenuate space charge build up in the material and the field distortion that goes with it. As a consequence, the material could withstand higher field. This is one view of the breakdown mechanism. An alternative explanation would be the role of nodules as barrier to microcracks where they can improve electrical treeing resistance as well.

Previous works on incorporation of nano and/or micro inorganic-fillers to the epoxy network has shown globally a decrease in the breakdown voltage value. These fillers had higher electrical conductivity and permittivity values with respect to the pure epoxy matrix and thus acted as defects in the material favoring the breakdown at lower voltages [6],[19],[20],[48]. In our studied blends, the PEI nodules have similar electrical conductivity values as well as lower permittivity where there was an enhancement in the breakdown voltage of the blend with respect to the pure epoxy network. This increase in the value can be due to the form of the micro-nodules of PEI that are distributed into the epoxy matrix as well. 


\section{Conclusion}

In this paper, electrical characterization of an organic-organic blend composed of epoxy with homogenously distributed thermoplastic nodules is examined and compared to the pure epoxy system. All measurements were studied at room temperature. Current measurements demonstrated Ohmic conduction phenomenon below the threshold field. Above the threshold field two possible approaches were studied. It is suggested that the current is controlled by volume phenomena through SCLC approach. Schottky model was also investigated and could also explain the features. Both materials DM and DM10PEI showed contact emission phenomenon at the interface between the electrodes and the sample. Further studies must be considered for this kind of measurement with variation of temperatures and especially monitoring the distribution of the space charge inside the sample. Monitoring the space charge will also give a wider vision on the breakdown voltage mechanism that has shown an increase in the strength with the increase of the wt $\%$ of PEI into the epoxy network. This enhancement is rarely seen in literature especially with the incorporation of micro-fillers as they act as defects. It can be explained by two different aspects. The first aspect is by taking into consideration that the PEI nodules, homogenously distributed in the epoxy network as seen by means of TEM, might act as obstacles for the breakdown voltage of the blends. The second aspect is by considering the fact that the blends have higher conductivity than the pure epoxy network; this leads to the possibility of the attenuation of the buildup of space charge in the material and consequently giving the blend the ability to withstand higher applied fields. Thus further investigations precisely monitoring the distribution of the space charge inside the sample are needed to confirm these assumptions.

\section{Acknowledgements}

The authors wish to thank Pierre Alcouffe for realizing the TEM image at the Centre Technologique des Microstructures CT $\mu$ of the University of Lyon. The French Ministry of Education and Research is gratefully recognized for providing a grant for this project and the Ecole Doctorale Electronique Electrotechnique Automatique de Lyon ED160 for their financial support.

\section{References}

[1] Fukunaga, K., Tan, M. \& Takehana, H. New partial discharge detection method for live UHV/EHV cable joints. IEEE Transactions on Electrical Insulation 27, 669-674 (1992).

[2] Nadolny, Z., Braun, J. M. \& Densley, R. J. Investigation of partial discharge pulse shapes occurring at interfaces in model joints. in Proceedings of the 1998 IEEE 6th International Conference on Conduction and Breakdown in Solid Dielectrics, 1998. ICSD '98 119-122 (1998).

[3] Dakin, T. W. Application of Epoxy Resins in Electrical Apparatus. IEEE Transactions on Electrical Insulation EI-9, 121-128 (1974). 
[4] Imai, T. et al. Effects of nano- and micro-filler mixture on electrical insulation properties of epoxy based composites. IEEE Transactions on Dielectrics and Electrical Insulation 13, 319-326 (2006).

[5] Tanaka T. Dielectric nanocomposites with insulating properties. IEEE Transactions on Dielectrics and Electrical Insulation 2005;12: 914-28.

[6] Iyer, G., Gorur, R. S., Richert, R., Krivda, A. \& Schmidt, L. E. Dielectric properties of epoxy based nanocomposites for high voltage insulation. IEEE Transactions on Dielectrics and Electrical Insulation 18, 659-666 (2011).

[7] Tsekmes IA, Morshuis PHF, Smit JJ, Kochetov R. Enhancing the thermal and electrical performance of epoxy microcomposites with the addition of nanofillers. IEEE Electrical Insulation Magazine 2015;31:32-42.

[8] Anderson, B. J. Thermal stability and lifetime estimates of a high temperature epoxy by Tg reduction. Polymer Degradation and Stability 98, 2375-2382 (2013).

[9] Hedrick JL, Yilgör I, Wilkes GL, McGrath JE. Chemical modification of matrix Resin networks with engineering thermoplastics. Polymer Bulletin 1985;13:201-8.

[10] Bonnet, A., Lestriez, B., Pascault, J. P. \& Sautereau, H. Intractable high-Tg thermoplastics processed with epoxy resin: Interfacial adhesion and mechanical properties of the cured blends. J. Polym. Sci. B Polym. Phys. 39, 363-373 (2001).

[11] Oyanguren PA, Riccardi CC, Williams RJJ, Mondragon I. Phase separation induced by a chain polymerization: Polysulfone-modified epoxy/anhydride systems. J Polym Sci B Polym Phys 1998;36:1349-59.

[12] Bonnet A, Pascault JP, Sautereau H, Taha M, Camberlin Y. Epoxy-Diamine Thermoset/Thermoplastic Blends. 1. Rates of Reactions before and after Phase Separation. Macromolecules 1999;32:8517-23.

[13] Guo, J. et al. Study on electrical properties of micro-nano structured epoxy composites. in Proceedings of 2014 International Symposium on Electrical Insulating Materials 441-444 (2014)

[14] Zhou, W. Effect of coupling agents on the thermal conductivity of aluminum particle/epoxy resin composites. J Mater Sci 46, 3883-3889 (2011).

[15] Khan, R. et al. Facile synthesis of epoxy nanocomposite coatings using inorganic nanoparticles for enhanced thermo-mechanical properties: a comparative study. J Coat Technol Res 13, 159-169 (2015).

[16] Lee, J. \& Yee, A. F. Inorganic particle toughening I: micro-mechanical deformations in the fracture of glass bead filled epoxies. Polymer 42, 577-588 (2001).

[17] Kinloch, A. J. et al. Toughening structural adhesives via nano- and micro-phase inclusions. The Journal of Adhesion 79, 867-873 (2003).

[18] Balakrishnan, S., Start, P. R., Raghavan, D. \& Hudson, S. D. The influence of clay and elastomer concentration on the morphology and fracture energy of preformed acrylic rubber dispersed clay filled epoxy nanocomposites. Polymer 46, 11255-11262 (2005).

[19] Li, Z., Okamoto, K., Ohki, Y. \& Tanaka, T. Effects of nano-filler addition on partial discharge resistance and dielectric breakdown strength of Micro-A12O3Epoxy composite. IEEE Transactions on Dielectrics and Electrical Insulation 17, 653-661 (2010).

[20] Hu, Y., Smith, R. C., Nelson, J. K. \& Schadler, L. S. Some mechanistic understanding of the impulse strength of nanocomposites. in 2006 IEEE Conference on Electrical Insulation and Dielectric Phenomena 31-34 (2006).

[21] Singha, S. \& Thomas, M. J. Dielectric properties of epoxy nanocomposites. IEEE Transactions on Dielectrics and Electrical Insulation 15, 12-23 (2008).

[22] Imai, T. et al. Improving Epoxy-based Insulating Materials with Nano-fillers toward Practical Application. in Conference Record of the 2008 IEEE International Symposium on Electrical Insulation, 2008. ISEI 2008 201204 (2008).

[23] Ding, H. Z. \& Varlow, B. R. Effect of nano-fillers on electrical treeing in epoxy resin subjected to AC voltage. in 2004 Annual Report Conference on Electrical Insulation and Dielectric Phenomena, 2004. CEIDP '04 332335 (2004).

[24] Singha, S. \& Thomas, M. J. Influence of filler loading on dielectric properties of epoxy-ZnO nanocomposites. IEEE Transactions on Dielectrics and Electrical Insulation 16, 531-542 (2009).

[25] Kochetov, R. et al. The effect of nanosilica on the DC breakdown strength of epoxy based nanocomposites. in 2014 IEEE Conference on Electrical Insulation and Dielectric Phenomena (CEIDP) 715-718 (2014).

[26] Tsekmes, I. A., Kochetov, R., Morshuis, P. H. F. \& Smit, J. J. AC breakdown strength of epoxy-boron nitride nanocomposites: Trend \& reproducibility. Electrical Insulation Conference (EIC), 446-449 (IEEE, 2015). 
[27] Preetha, P. \& Thomas, M. J. AC breakdown characteristics of epoxy alumina nanocomposites. in 2010 Annual Report Conference on Electrical Insulation and Dielectric Phenomena (CEIDP) 1-4 (2010).

[28] Tuncer, E. et al. Electrical properties of epoxy resin based nano-composites. Nanotechnology 18, 25703 (2007).

[29] Girard-Reydet E, Vicard V, Pascault JP, Sautereau H. Polyetherimide-modified epoxy networks: Influence of cure conditions on morphology and mechanical properties. J Appl Polym Sci 1997;65:2433-45.

[30] Riccardi, C. C. et al. Thermodynamic analysis of the phase separation in polyetherimide-modified epoxies. J. Polym. Sci. B Polym. Phys. 34, 349-356 (1996).

[31] Laurent, C. \& Teyssedre, G. Hot electron and partial-discharge induced aging of polymers. Nucl. Instr. and Meth. in Phys. Res. B 208, 442-447 (2003)

[32] Teyssedre, G., Berquez, L. \& Laurent, C. Some aspects of coupled electrical-mechanical effects in dielectric materials. Eur. Phys. J: Appl. Phys. 70, 20902-01/09 (2015)

[33] Personal communication: Halawani, N., Augé, J. L., Morel, H., Gain, O. \& Pruvost, S. Electrical, thermal and mechanical properties of poly-etherimide epoxy-diamine blend. Composites Part B: Engineering 110, 530-541 (2017)

[34] Gupta, D. K. D. \& Joyner, K. On the nature of absorption currents in polyethyleneterephthalate (PET). J. Phys. D: Appl. Phys. 9, 829 (1976).

[35] Jonscher, A. K. Frequency-dependence of conductivity in hopping systems. Journal of Non-Crystalline Solids 8, 293-315 (1972).

[36] Guillermin, C., Rain, P. \& Rowe, S. W. Transient and steady-state currents in epoxy resin. J. Phys. D: Appl. Phys. 39, 515 (2006).

[37] Mizutani, T. Space charge measurement techniques and space charge in polyethylene. IEEE Transactions on Dielectrics and Electrical Insulation 1, 923-933 (1994).

[38] O'Dwyer, J. J. The theory of electrical conduction and breakdown in solid dielectrics. (Clarendon Press, 1973).

[39] Alam, M. A., Azarian, M. H. \& Pecht, M. G. Modeling the Electrical Conduction in Epoxy-BaTiO3 Nanocomposites. Journal of Elec Materi 42, 1101-1107 (2013).

[40] Many, A. \& Rakavy, G. Theory of Transient Space-Charge-Limited Currents in Solids in the Presence of Trapping. Phys. Rev. 126, 1980-1988 (1962).

[41] Castellon J, Nguyen HN, Agnel S, Toureille A, Frechette M, Savoie S, et al. Electrical properties analysis of micro and nano composite epoxy resin materials. IEEE Transactions on Dielectrics and Electrical Insulation 2011;18:651-8.

[42] Krivda, A. et al. Characterization of epoxy microcomposite and nanocomposite materials for power engineering applications. IEEE Electrical Insulation Magazine 28, 38-51 (2012).

[43] Dissado, L. A. \& Fothergill, J. C. Electrical Degradation and Breakdown in Polymers. (IET, 1992).

[44] Dissado, L. A., Fothergill, J. C., Wolfe, S. V. \& Hill, R. M. Weibull Statistics in Dielectric Breakdown; Theoretical Basis, Applications and Implications. IEEE Transactions on Electrical Insulation EI-19, 227-233 (1984).

[45] Nascimento, E. do et al. Breakdown, free-volume and dielectric behavior of the nanodielectric coatings based on epoxy/metal oxides. J Mater Sci: Mater Electron 27, 9240-9254 (2016).

[46] Li B, Zhong W-H. Influence of Carbon Nanofiber Network Variability on the AC Conductivity of Polyetherimide Composite Films. Macromolecular Materials and Engineering 2010;295:310-4. doi:10.1002/mame.200900291.

[47] Chen G., Zhao J., Li S., Zhong L. Origin of thickness dependent de electrical breakdown in dielectrics. Appl. Phys. Lett. 100, 222904 (2012)

[48] Nelson, J. K. \& Fothergill, J. C. Internal charge behavior of nanocomposites. Nanotechnology 15, 586-595 (2004) 
List of Figure's captions:

Figure 11: Polarization current curves at $5 \mathrm{kV}$ for DM and DM10PEI

Figure 12: Absorption and depolarization currents under $5 \mathrm{kV}$ for a) DM and b) DM10PEI

Figure 13: Isochronal currents obtained from depolarization current

Figure 14: Conduction current density versus applied electric field

Figure 15: In (conductivity) versus $\sqrt{E}$ at room temperature: with $\sigma(\mathrm{S} / \mathrm{cm})$.

Figure 16: Representation of conduction data in a Fowler-Nordheim plot

Figure 17: J versus $\sqrt{E_{C}}$ for Schottky

Figure 18: a) TEM image of DM5PEI and b) AFM image of DM10PEI

Figure 19: Weibull distribution plot (95\% confidence interval) for DM, PEI, DM5PEI and DM10PEI

Figure 20: SEM images of the breakdown channel in DM10PEI sample a) face view and b) side view after breaking the sample as illustrated in the schemas

\section{List of table Captions:}

Table 3: Obtained slopes of I-E curves from isochronal plots

Table 4: Scale and shape parameter from Weibull distribution 